\title{
The Effect of Fox News Channel on U.S. Elections: 2000-2020
}

Working Paper

Author(s):

Ash, Elliott; Galletta, Sergio; Pinna, Matteo; Warshaw, Christopher

Publication date:

2021-04

Permanent link:

https://doi.org/10.3929/ethz-b-000484661

Rights / license:

In Copyright - Non-Commercial Use Permitted

Originally published in:

Center for Law \& Economics Working Paper Series 2021(07) 


\section{$\boldsymbol{G H}$ zürich}

\section{Center for Law \& Economics Working Paper Series}

Number 07/2021

The Effect of Fox News Channel on U.S. Elections: $2000-2020$

Elliott Ash

Sergio Galletta

Matteo Pinna

Christopher Warshaw

April 2021 


\title{
The Effect of Fox News Channel on U.S. Elections: $2000-2020$ *
}

\author{
Elliott Ash ${ }^{1}$, Sergio Galletta ${ }^{2,1}$, Matteo Pinna ${ }^{1}$, Christopher Warshaw ${ }^{3}$ \\ ${ }^{1}$ ETH Zürich \\ ${ }^{2}$ University of Bergamo \\ ${ }^{3}$ George Washington University
}

\begin{abstract}
This paper provides a comprehensive assessment of the effect of Fox News Channel (FNC) on elections in the United States. FNC is the highest-rated channel on cable television and has a documented conservative slant. We show that FNC has helped Republican candidates in elections across levels of U.S. government over the past decade. A one standard deviation decrease in FNC's channel position boosted Republican vote shares by at least .5 percentage points in recent presidential, Senate, House and gubernatorial elections. The effects of FNC increased steadily between 2004 and 2016 and then plateaued. Survey-based evidence suggests that FNC affects elections by shifting the political preferences of Americans to the right. Overall, the findings suggest that FNC has contributed to the nationalization of United States elections.
\end{abstract}

* This version: April 30, 2021; First version: April 2021

Email addresses: ashe@ethz.ch (Elliott Ash), sergio.galletta@unibg.it (Sergio Galletta), matteo.pinna@gess.ethz.ch (Matteo Pinna), warshaw@email.gwu.edu (Christopher Warshaw) 


\section{Introduction}

Fox News has dominated cable television over the past two decades. It routinely has the highest ratings of any channel on cable television, with about four million Americans tuning in at prime time and millions more watching at some point during an average week (Schneider, 2020). Moreover, it has a substantial conservative slant that has become more pronounced over time (Groseclose and Milyo, 2005; Budak, Goel, and Rao, 2016; Martin and Yurukoglu, 2017). The popularity and partisan messaging on Fox News might shift the political preferences and voting behavior of the American public (Yglesias, 2018).

Several recent papers have shown that Fox News Channel has influenced voting in presidential elections in the United States (DellaVigna and Kaplan, 2007; Hopkins and Ladd, 2014; Martin and Yurukoglu, 2017). In particular, the instrumental variables analysis from Martin and Yurukoglu (2017) shows that exogenous increases in Fox News viewership due to the channel position increased Republican vote share in the 2008 presidential election. They argue that their estimates indicate that FNC may have boosted Republicans' overall vote share by 6 percentage points in the 2008 presidential elections.

Given these findings, it is notable that there has not been much follow-up work on how Fox News has influenced more recent presidential elections or down-ballot elections (Yglesias, 2018). Two previous studies have examined the effect of the roll-out of Fox News on House elections, with one finding no effect (Clinton and Enamorado, 2014), and another finding an increase in the frequency of effective challenges to Democratic incumbents (without looking at election margins) (Arceneaux et al., 2020). ${ }^{1}$ Moreover, no previous study has examined the impact of Fox News on elections for other offices, such as the Senate or governors. It is also unclear whether the electoral effect of Fox

\footnotetext{
${ }^{1}$ In addition, several previous studies have analyzed the effect of FNC on Congress members' issue positions. These studies have shown that FNC shifted roll call voting patterns to the right (Clinton and Enamorado, 2014; Arceneaux et al., 2016).
} 
News grew or diminished over the past decade.

In this paper, we provide a comprehensive examination of whether Fox News Channel (FNC) has affected elections for President, U.S. House, U.S. Senate, and governors over the past two decades. We use FNC's channel position as an instrumental variable (IV) that exogenously shifts viewership (Martin and Yurukoglu, 2017; Galletta and Ash, 2019; Ash et al., 2020). We find that FNC has helped Republicans at each of these levels of office. A one standard deviation decrease in FNC's channel position boosted Republican vote share by about .6 percentage points in recent (2020) presidential elections. The effects are similar in Senate races and slightly larger in House races. In gubernatorial races, the effect comes later but is of similar magnitude in the most recent elections. Overall, the evidence suggests that the effects of FNC increased steadily over time between 2004 and 2016, with some heterogeneity across elections.

Given both the similarity of our findings across offices and the uniform national coverage on Fox News, it seems unlikely that Fox News is influencing Americans' evaluation of individual down-ballot candidates. Instead, the primary mechanism for FNC's effect on elections appears to be that it changes the underlying political preferences of Americans. Using survey data on self-reported political attitudes from 2000-2020, we find that FNC increases the percentage of surveyed Americans identifying as Republicans. We also find suggestive evidence that it pushes surveyed Americans' policy ideology, based on their preferences on issue positions, to the right.

Overall, our findings indicate that Fox News has substantial effects up and down the ballot, and is probably contributing to the nationalization of American elections (Hopkins, 2018). We proceed as follows. First, we discuss our research design and data. Next, we discuss our findings, including both the effect of FNC on elections and surveybased evidence on its effects on the political preferences of Americans. Finally, we briefly conclude. 


\section{Methods}

Fox News started rolling out on U.S. cable systems in 1996 and by 2004 it was available to the vast majority of cable television subscribers (Appendix Figure S.3). Since then, it has routinely had the highest ratings of any channel on cable television (Schneider, 2020). It is challenging, however, to determine the causal effect of Fox News on politics due to the endogeneity of viewing decisions. Places that have a pre-existing conservative slant will have a stronger preference to watch FNC, so correlations between political choices and Fox viewership may be confounded.

To identify the effect of Fox News on elections, we use channel position as an instrumental variable (IV), as in Martin and Yurukoglu (2017). We exploit the fact that channels' positions in the cable system lineup are exogenously determined, and that on average, viewers flipping through channels tend to spend more time watching programs in channels that are lower in the lineup.

We examine the effect of Fox News on presidential, House, Senate, and gubernatorial races from 1998-2020. ${ }^{2}$ Ideally, we would provide first-stage and two-stage least-squares (2SLS) results for all years with elections. Due to data availability, however, we observe and use the endogenous regressor (FNC ratings) only for the years 2005, 2006, 2008, and 2020. ${ }^{3}$ Therefore, our main analysis focuses on the reduced form, where the outcomes (vote shares) are regressed directly on the instrument (FNC channel position). ${ }^{4}$ To make the reduced-form more interpretable, the channel positions are standardized by dividing the original variable by its standard deviation. We will still use the data on ratings to test for instrument relevance and to validate conditional exogeneity of the instrument.

\footnotetext{
${ }^{2}$ In the Appendix, we also provide evidence on its effect on down-ballot state-level offices such as State Attorney Generals.

${ }^{3}$ See Appendix S.1 for more details on our data, including information about Fox News, election outcomes, and survey data.

${ }^{4}$ We have data on channel position covering almost all this period: 1998-2016. Channels do not change much over time within county.
} 
Our estimation approach consists of a series of cross-sectional regressions with countylevel data, run separately for each of the four election types (president, House, Senate, governor) and for each election year. For presidential elections, we have a set of six elections taking place every four years, 2000-2020. For House and Senate elections, there are 12 election cycles between 1998-2020. Gubernatorial elections are fewer and more irregular, so we pool elections over four year periods (1999-2002, 2003-2006, 2007-2010, 2011-2014, and 2015-2018). ${ }^{5}$

Taken together, our main empirical analysis comprises 36 reduced-form regressions. For each election type and election year, we estimate

$$
\text { Rep Vote Share }{ }_{i}=\alpha \text { FNC Channel position }{ }_{i}+\lambda_{s}+\gamma \mathbf{X}_{i}+\varepsilon_{i}
$$

where Rep Vote Share $i$ is the main outcome, vote share for Republican Party in county $i$. FNC Channel position $_{i}$ is our instrument, giving FNC channel position in the system lineup in county $i$ in the associated election year. $\lambda_{s}$ includes state fixed effects, while $X_{i}$ includes county-level covariates. The set of time-invariant covariates includes Republican presidential vote share in 1996 (prior to the advent of Fox News) and population shares across a number of socio-demographic categories and characteristics of the county: gender, race/ethnicity groups (Black, White, Hispanic, Asian-American), land area, population density, those living in urban/rural areas, those with a college degree, working-age share of population, and proportion eligible for food stamps. Time-varying controls include the share of population with access to Fox News and ratings for the other cable news networks, MSNBC and CNN. Finally, $\varepsilon_{i}$ is the error term. The coefficient of interest is $\alpha$, which is estimated separately for each election type and election year.

\footnotetext{
${ }^{5}$ Due to minor changes in the availability of voting and ratings data over time, the sample of counties is slightly different across years and election types. The results are consistent when limiting to the subset of counties for which all data are available.
} 
Observations are weighted by county population. For inference and confidence intervals, standard errors are clustered by state. ${ }^{6}$

We show relevance of the instrument by estimating the first-stage equation

$$
\text { FNC Viewership }_{i}=\beta \text { FNC Channel } \text { position }_{i}+\lambda_{s}+\gamma \mathbf{X}_{i}+\eta_{i}
$$

where FNC Viewership $i$ is FNC ratings in county $i$, while the other elements are as previously defined. As done in Martin and Yurukoglu (2017), Appendix Figure S.2 reports the first stage when pooling (with State-Year FE's) the data from those years for which we have available ratings and elections information (i.e., 2005, 2006, 2008 and 2020), showing a first-stage F-statistic of 14.26. If the data is not pooled and separate first-stage coefficients are estimated, they are stable across years.

For completeness, Appendix Figure S.6 reports two-stage least squares estimates using the second-stage equation

$$
\text { Rep Vote } \text { Share }_{i}=\delta \text { FNC Viewership } i+\lambda_{s}+\gamma \mathbf{X}_{i}+\phi_{i}
$$

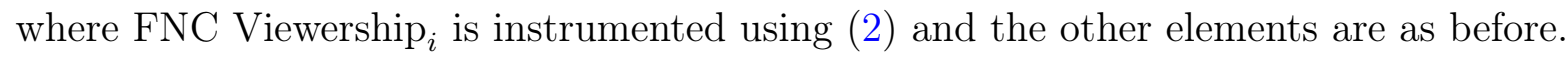
Therefore $\delta$ identifies the local average treatment effects by election type and year. Again, we limit to election years for which we have ratings, but we obtain qualitatively similar results for the other election years if ratings are imputed or interpolated. For comparison, Appendix Figure S.7 reports ordinary least squares (OLS) estimates of (3).

Besides relevance, the other assumption of IV estimation is exogeneity of the instrument. ${ }^{7}$ Following Martin and Yurukoglu (2017), we provide a number of tests to validate

\footnotetext{
${ }^{6}$ Similar standard error estimates are obtained with clustering by media market area, or without clustering. Results are also similar when not including sample weights (see Figure S.13).

${ }^{7}$ The exclusion restriction is not as much of an issue, as channel position number is unlikely to affect voting through other factors besides viewership (Martin and Yurukoglu, 2017).
} 
this assumption. First, we show that counties whose socio-demographic characteristics predict a high FNC rating do not have a systematically lower channel position. Formally, we estimate the reduced form Equation (1) where the outcome is a linear prediction for ratings based on demographics, and the right-hand-side variable is FNC channel position. These estimates, reported in Appendix Table S.2 column (1), show that channel position is not correlated with demographics that would otherwise predict high ratings. Second, we apply a similar procedure but analyzing socio-demographic characteristics that predict electoral outcomes. The results, reported in Appendix Table S.2 columns (2-3), show that channel position is not correlated with vote-share-relevant demographics. Third and finally, Appendix Table S.2, column (4) shows that channel position is not correlated with Republican vote share in 1996 presidential elections (before the introduction of FNC). These results are reassuring that "endogenous" channel position manipulation is unlikely to have taken place. ${ }^{8}$

\section{Results}

This section presents our results. First, we show the results for presidential elections from 2000-2020. Next, we proceed to down-ballot elections, showing results for House, Senate, and gubernatorial elections. Third, we look at self-reported political attitudes. The estimates are reported as coefficient plots from the reduced-form model (1), plotted by year with $95 \%$ confidence intervals. $^{9}$

\section{Presidential Elections}

Figure 1 shows the results for presidential elections. Consistent with DellaVigna and Kaplan (2007) and Martin and Yurukoglu (2017), we find evidence that exposure to Fox News Channel increases voting for Republican presidential candidates in the most recent

\footnotetext{
${ }^{8}$ Further validation tests are provided in Appendix Figure S.9

${ }^{9}$ The results here are presented graphically. Table S.4 in Appendix S.3 shows a table with all the results.
} 
Figure 1: Reduced Form effect of Fox News on US Presidential elections

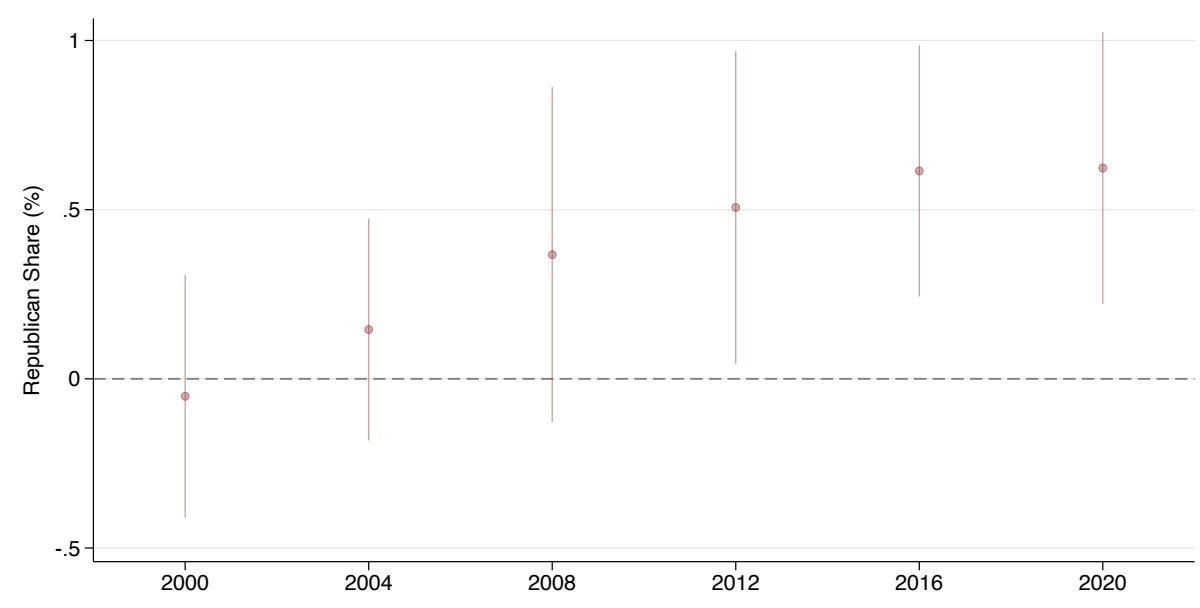

Notes: Reduced Form (RF) regression results (Equation 1) for the effect of FNC on elections outcomes at the county level. For each year of elections we use the corresponding year's channel position, except for 2020 (2016 positions). Channel positions are inverted and standardized by their standard deviation.

elections. In the earliest elections (2000 and 2004), there is not much of an effect yet of Fox News due to channel positioning, perhaps because Fox viewership was still growing. Our 2008 estimate of $\hat{\alpha}_{e}=.37$ is similar in magnitude to the estimate from Martin and Yurukoglu (2017), although not statistically significant. ${ }^{10}$ This estimate indicates that a one-standard-deviation decrease in FNC channel position increased Republicans' presidential vote share by about .37 percentage points.

Our analysis further builds on the previous papers by estimating the FNC effects on the 2012, 2016, and 2020 elections. We find that those effects have gotten larger over time. A one standard deviation decrease in Fox News' channel position increased Republicans' presidential two-party vote share by about .5\% in 2012 and about .6\% in 2016 and 2020.

These results suggest that partisan cable news has had a substantial influence on at least the last four presidential elections in the United States. Indeed, in 2016 Donald

\footnotetext{
${ }^{10}$ The equivalent estimate from Martin and Yurukoglu (2017) would be $\hat{\alpha}_{e} \approx .3$. Their estimate is statistically significant, likely because they use zipcode-level data. Further, the Martin and Yurukoglu (2017) appendix shows similar results to ours using partial data from the 2004 and 2012 elections.
} 
Trump won the electoral college "tipping point" state of Pennsylvania by .7\% and in 2020 Joe Biden won the tipping point state of Wisconsin by .6\%. Fox News could have easily tipped vote shares enough to flip these narrow margins.

\section{Down-Ballot Elections}

The next question is whether the effects on presidential elections extend to downballot races. Figure 2 reports equivalent coefficient plots for the House (panel a), Senate (panel b), and Governor (panel c). For House and Senate races, we report results by election cycle. For gubernatorial races, we pool across four-year periods.

Overall, the effects of FNC in down-ballot elections are qualitatively similar to, though less precise than, those in presidential elections. In House elections, we see a positive (Pro-Republican) coefficient on FNC for Republicans' two-party vote share in 2012, and it becomes statistically significant starting 2018. Since around 2012, a one standard deviation decrease in FNC's channel position has led to about a .6 to 1.6 percentage point increase in Republican vote shares. In Senate elections, we have a positive coefficient starting in 2006, which becomes statistically significant starting $2014 .^{11}$ Since then, there have been relatively consistent year-to-year effects of around .5 to .75 percentage points. In gubernatorial races, FNC had a small and not statistically significant effect until the latter half of the 2010s. In recent elections, however, the effect of FNC in gubernatorial races is similar to Senate races - increasing Republican vote share by about .6 percentage points. ${ }^{12}$

Thus, despite the national focus of its content, Fox News has had an effect on races at the subnational level. These include Senate races for the 50 states, House races for the 435 Congressional districts, and even for governors - who are involved with state politics

\footnotetext{
${ }^{11}$ It is significant at the $10 \%$ level in 2014 and at the $5 \%$ level in 2016, 2018, and 2020.

${ }^{12}$ There is a similar, slightly stronger, effect in the 2019-2020 governor elections, which are omitted because of low sample size. In Appendix S.4, we examine additional down-ballot statewide races, such as Attorney General elections. We have less data on these races, and the estimates are noisy across years. FNC seems to affect Attorney General and Treasurer races, though not Secretary of State races.
} 
Figure 2: Reduced Form effect of Fox News on Down-Ballot Elections

(a) House Elections

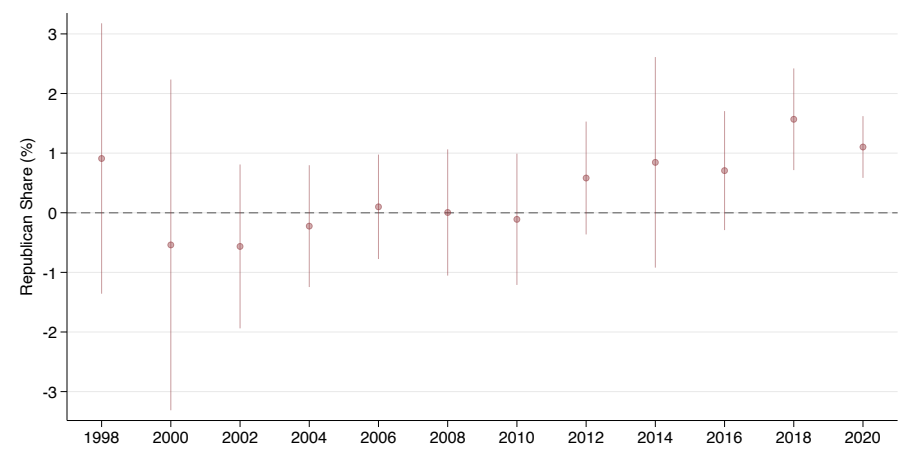

(b) Senate Elections

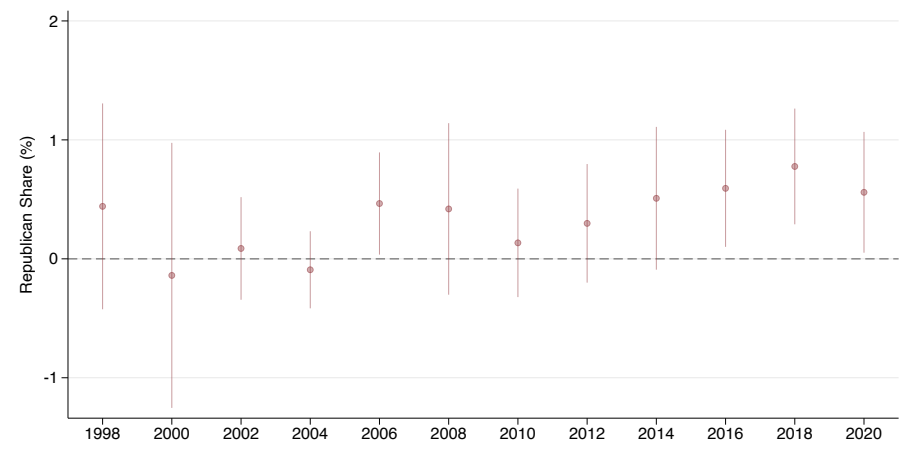

(c) Governor Elections

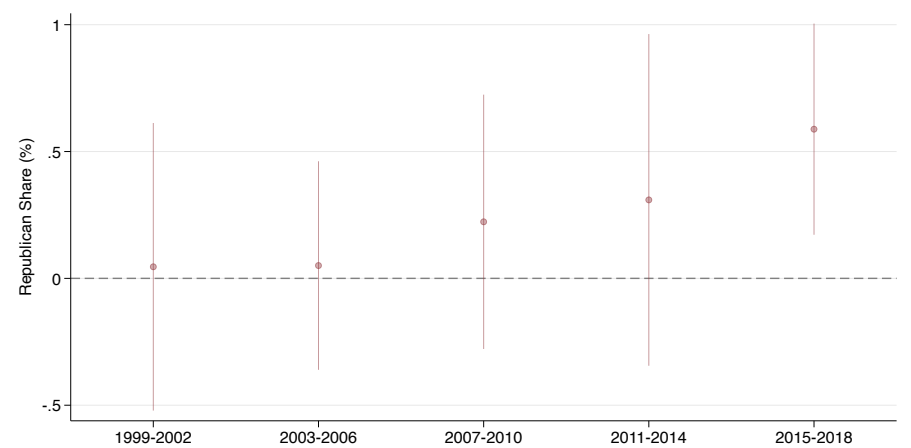

Notes: Reduced Form (RF) regression results (Equation 1) for the effect of FNC on elections outcomes at the county level. For each year of elections we use the corresponding year's channel position, except for 2018-2020 (2016 positions).

rather than national politics. This effect likely reflects the growing nationalization of state politics, whereby they are influenced more by partisanship and national trends rather than state-specific factors (Hopkins, 2018). 


\section{Effect on Political Attitudes}

The uniformity of Fox New's effect on elections across levels of government suggests that FNC is not simply influencing Americans' views about particular candidates. Rather, FNC appears to be influencing the underlying partisanship and ideology of the American electorate, which, in turn, shifts Americans' voting behavior in a proRepublican direction.

In this section, we examine this possible mechanism for our main results using survey data on the preferences of approximately 661,000 Americans between 2000-2020 from the National Annenberg Election Survey (NAES) and the Cooperative Congressional Election Study (CCES). First, we examine the effect of FNC on the percentage of respondents in each county that self-identify as Republicans. Second, we examine the effect of FNC on Americans' left-right policy ideology ("ideal points") based on their responses to dozens of policy issue questions (Tausanovitch and Warshaw, 2013). ${ }^{13}$

Figure 3 shows the results. The top panel shows the effect of FNC on the percentage of respondents in each county that report to be Republicans. Starting in the 2006-2008 period, we find a positive effect, which is statistically significant at the 10 percent level. A one-standard-deviation decrease in FNC's channel position increases the share of Republican voters by about .75 percentage points. The bottom panel shows the effect of FNC on the ideological preferences of the American public. While these estimates are noisy, they overall indicate a rightward shift in ideology. The effect is statistically significant at $5 \%$ in 2004, and statistically significant at $10 \%$ in 2013-2016. A one standard deviation decrease in FNC's channel position shifts the average American's ideological position by about .01 standard deviations to the right in recent years.

\footnotetext{
${ }^{13}$ These are based on a two-parameter IRT model that estimates respondents' ideal points using their policy responses on these surveys (Clinton, Jackman, and Rivers, 2004). This model assumes that the survey respondents' policy preferences are a function of their latent ideology (Tausanovitch and Warshaw, 2013). The outcome is standardized to mean zero and variance one.
} 
Figure 3: Reduced Form effect of Fox News on Self-Reported Political and Ideological Preferences

(a) Self-Reported Partisanship

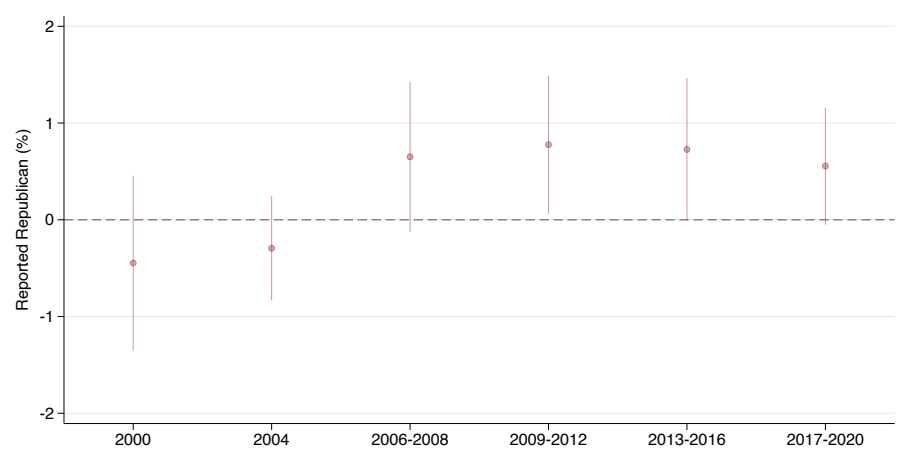

(b) Policy Ideology

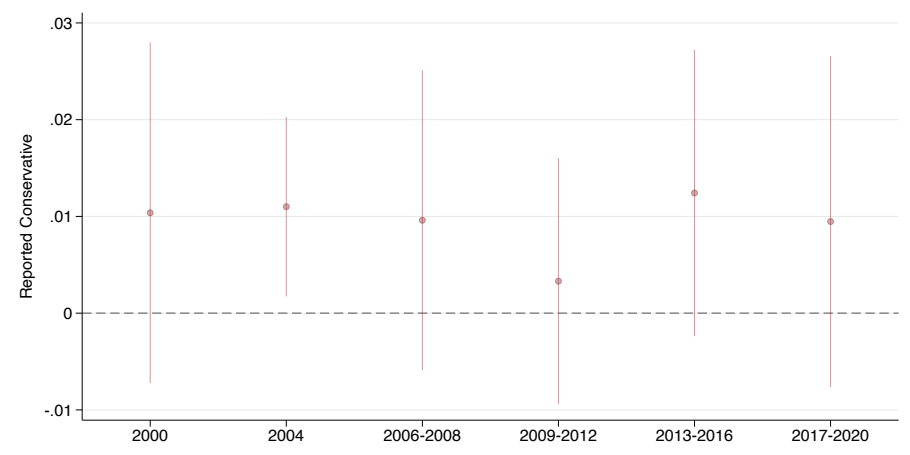

Notes: Reduced Form (RF) regression results (Equation 1) for the effect of FNC on Americans' partisanship and ideology. For each year of elections we use the corresponding year's channel position, except for 2017-2020 (2016 positions). When possible, we aggregate by election cycle.

Overall, these results indicate that the mechanism for the effect of FNC on elections is that it's shifting the political preferences of Americans to the right. We see that shift in self-reported party affiliation and in responses to questions about ideological policies. This evidence complements the finding in Galletta and Ash (2019) that Fox News exposure changes fiscal policy views, as expressed in voting on taxation-related ballot referendums.

\section{Robustness Checks}

Appendix S.5 shows that the results are robust to a wide variety of robustness checks. For instance, our specification is robust to various changes in the set of controls and to 
geography-based sub-sampling. Placebo checks show a null effect for pre-treatment partisanship and when looking at the other cable news networks CNN and MSNBC (Figure S.8). When splitting the sample by partisanship or ideology, the estimates suggest a stronger effect of Fox News for Democratic/liberal counties, though the difference is not statistically significant. Alternative survey measures also deliver similar results.

\section{Conclusion}

We have shown that FNC has helped Republican candidates across levels of U.S. government, especially in the most recent elections. A one standard deviation decrease in FNC's channel position boosted Republicans by between .5 and 1.5 percentage points in recent presidential, Senate, House and gubernatorial elections. Moreover, the key mechanism for the effect of FNC on elections is that it's shifting the political preferences of Americans - increasing the share of Republicans in each county and pushing their ideological preferences to the right.

The effect sizes are substantively quite large. Indeed, the effect of just a one standard deviation shift in FNC's channel position (roughly 29 positions), which induces about 7 minutes of additional viewership per week, is larger than the effect of a one standard deviation change in local real wages (de Benedictis-Kessner and Warshaw, 2020) or in exposure to broadcast television political advertising (Sides, Vavreck, and Warshaw, 2020). Given the estimated effect sizes on presidential elections, for example, Fox News could have easily tipped the scales for Donald Trump in 2016.

This paper contributes to a growing literature on media effects in American politics (e.g., Martin and Yurukoglu, 2017; Martin and McCrain, 2019; Moskowitz, 2021; Levendusky, 2021). Partisan media can have substantial effects on U.S. elections up and down the ballot. Our findings show that Fox News is probably contributing to the nationalization of American elections (Hopkins, 2018). In addition, many of the previous results on Fox News could be explained in part by its effect on party affiliation and policy ideology 
(Galletta and Ash, 2019). The evidence provides more support for the view that FNC is skewing American Politics, contributing to a Republican advantage in elections and policy-making. 


\section{References}

Arceneaux, Kevin, Johanna Dunaway, Martin Johnson, and Ryan J Vander Wielen. 2020. "Strategic Candidate Entry and Congressional Elections in the Era of Fox News." American Journal of Political Science 64(2): 398-415.

Arceneaux, Kevin, Martin Johnson, René Lindstädt, and Ryan J. Vander Wielen. 2016.

"The Influence of News Media on Political Elites: Investigating Strategic Responsiveness in Congress." American Journal of Political Science .

Ash, Elliott, Sergio Galletta, Dominik Hangartner, Yotam Margalit, and Matteo Pinna. 2020. "The Effect of Fox News on Health Behavior During COVID-19.".

Budak, Ceren, Sharad Goel, and Justin M Rao. 2016. "Fair and balanced? Quantifying media bias through crowdsourced content analysis." Public Opinion Quarterly 80(S1): $250-271$.

Clinton, Joshua D, and Ted Enamorado. 2014. "The national news media's effect on Congress: How Fox News affected elites in Congress." Journal of Politics 76(4): 928943.

Clinton, Joshua, Simon Jackman, and Douglas Rivers. 2004. "The Statistical Analysis of Roll Call Data." American Political Science Review pp. 355-370.

de Benedictis-Kessner, Justin, and Christopher Warshaw. 2020. "Accountability for the Local Economy at All Levels of Government in United States Elections." American Political Science Review 114(3): 660-676.

DellaVigna, Stefano, and Ethan Kaplan. 2007. "The Fox News effect: Media bias and voting." The Quarterly Journal of Economics 122(3): 1187-1234.

Galletta, Sergio, and Elliott Ash. 2019. "How Cable News Reshaped Local Government." Available at SSRN 3370908 .

Groseclose, Tim, and Jeffrey Milyo. 2005. "A measure of media bias." The Quarterly Journal of Economics 120(4): 1191-1237. 
Hopkins, Daniel J. 2018. The increasingly United States: How and why American political behavior nationalized. University of Chicago Press.

Hopkins, Daniel J, and Jonathan M Ladd. 2014. "The Consequences of Broader Media Choice: Evidence from the Expansion of Fox News." Quarterly Journal of Political Science 9(1): 115-135.

Leip, Dave. 2016. "U.S. House General County Election Results." Available at https: //doi.org/10.7910/DVN/T2DQQS.

Levendusky, Matthew S. 2021. "How Does Local TV News Change Viewers' Attitudes? The Case of Sinclair Broadcasting." Political Communication pp. 1-16.

Martin, Gregory J, and Ali Yurukoglu. 2017. "Bias in cable news: Persuasion and polarization." American Economic Review 107(9): 2565-99.

Martin, Gregory J, and Joshua McCrain. 2019. "Local News and National Politics." American Political Science Review 113(2): 372-384.

Moskowitz, Daniel J. 2021. "Local News, Information, and the Nationalization of US Elections." American Political Science Review 115(1): 114-129.

Schneider, Michael. 2020. "Year in Review: Most-Watched Television Networks — Ranking 2020's Winners and Losers." Available at https://variety .com/2020/tv/news/ network-ratings-2020-top-channels-fox-news-cnn-msnbc-cbs-1234866801/.

Sides, John, Lynn Vavreck, and Christopher Warshaw. 2020. "The Effect of Television Advertising in United States Elections." Available at: http://chriswarshaw.com/ papers/advertising.pdf.

Tausanovitch, Chris, and Christopher Warshaw. 2013. "Measuring Constituent Policy Preferences in Congress, State Legislatures, and Cities." The Journal of Politics 75(2): $330-342$.

Yglesias, Matthew. 2018. "The case for Fox News studies." Political Communication 35(4): $681-683$. 


\section{Supplementary Materials}

\section{Contents}

S.1 Further information on data sources $\quad 2$

S.1.1 Channel positions ................. 2

S.1.2 Nielsen 2020 ratings . . . . . . . . . . . . . . 2

S.1.3 Elections data ..................... 3

S.1.4 Demographics and politics ........... 3

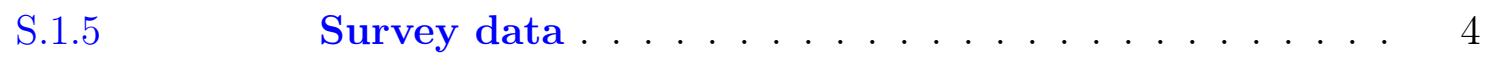

S.1.6 Electoral results and summary statistics . . . . . . 5

$\begin{array}{lll}\text { S.2 Instrument validity } & 7\end{array}$

S.2.1 First stage f..................... 7

S.2.2 Instrument placebo tests . . . . . . . . . 8

S.2.3 Fox News availability in the counties . . . . . . . . 10

$\begin{array}{lll}\text { S.3 Tables for main-text results } & 11\end{array}$

S.4 Additional down-ballot election and survey results 13

$\begin{array}{lll}\text { S.5 Robustness checks } & 15\end{array}$

S.5.1 Ordinary least squares and two stages least squares

of main regressions . . . . . . . . . . . . . . . . . . . 17

S.5.2 Other networks ................... 19

S.5.3 Pre-treatment placebo checks . . . . . . . . . 20

S.5.4 Heterogeneity by partisanship and ideology . . . . . . 21

S.5.5 Specification checks . . . . . . . . . . 23

S.5.6 Sample checks . . . . . . . . . . . . 26 


\section{S.1. Further information on data sources}

This appendix section provides additional information about our data. Summary statistics are reported in Table S.1.

\section{S.1.1. Channel positions}

Channel positions for FNC, MSNBC and CNN come from the Nielsen FOCUS database, which reports channel lineups of all U.S. local broadcast systems, with information about the area served by the system at the zipcode level. We use channel positions from 1998 to 2016, with 1996-1997 being assigned the 1998 value and 20172020 being assigned the 2016 value. This interpolation should be innocuous since channel positions are persistent over time. Similar to Galletta and Ash (2019) and Ash et al. (2020), we aggregate the data at the county level, by averaging zipcode-level channel positions with weighting by zipcode population. To limit the influence of outlier channels, we winsorize the channel position variables at the top and bottom deciles for all years. Throughout the analysis the channel position is inverted (taking the negative of the position), for presentation purposes and standardized by dividing by its standard deviation to facilitate understanding of the magnitude of the effects.

\section{S.1.2. Nielsen 2020 ratings}

Television viewership by county of FNC, MSNBC and CNN, is provided by Nielsen. The measure is "ratings," which is proportional to the number of minutes that each household tuned in to each specific channel during that year. Years used in the analysis are 2005, 2006, 2008, and 2020. We standardize the viewership throughout the paper to variance one.

For 2005-2008, viewership is the average for the year and is at the zipcode level. It is aggregate to the county level by averaging across zipcodes, weighted by the population. For 2020, the data is the average for January and February and is at the county level. 
Some counties in the 2020 data were split in parts (e.g. North County-A, East CountyA), and were aggregated together by simple average.

For completeness, we still produced OLS and 2SLS results for the years that were missing ratings data. Filling in the missing data was done as follows. For ratings before 2005, we use 2005 ratings. For years 2005 to 2008 and 2020 we use the respective years' ratings. For years 2009-2019 we use an interpolation of 2008 and 2020 ratings. Results are robust to variations of this assignment: e.g. using a specific year of ratings for all years, using different averages of available years or using the closest available year of ratings.

\section{S.1.3. Elections data}

We use a comprehensive dataset of county-level election returns from 1996-2020. For presidential, senate, and gubernatorial elections, we used data from CQ's Voting and Elections Collection. For House elections, we used data from the Atlas of U.S. Elections (Leip, 2016). For other state offices (i.e., attorney general and treasurer), we used crowdsourced county-level data from OurCampaigns.com. ${ }^{14}$

\section{S.1.4. Demographics and politics}

The data on local demographics come from the 2010 U.S. Census. The main specification includes the following set of controls for the counties (other than network related controls): population (used as weighting), population density, land area, working-age share of population aged 20-69 over other ages, proportion eligible for food stamps, black population share, white population share, hispanic population share, asian population share, proportion of male sex, share of population with a college degree, share of population living in rural areas and share that lives in urban areas. In some robustness checks we use a reduced set of controls for socio-demographics including only: age controls,

\footnotetext{
${ }^{14}$ Thirty-six states elect state treasurers and 43 elect attorneys general.
} 
food stamps and population density. We also use an extended set of controls, adding: share of people with no high school education, or with high school as higher education, and occupation shares for: management and professional; service; sales and office; construction, extraction and maintenance; production, transportation and material moving occupations.

Data on political attitudes include Republican vote share from the pre-FNC 1996 presidential election.

\section{S.1.5. Survey data}

We have a variety of large-scale surveys from 2000-2020, including the 2000 and 2004 National Annenberg Election Survey (NAES) and the 2006-2020 Cooperative Congressional Election Study (CCES) surveys. Overall, we have data on the preferences of approximately 661,000 Americans. We focus on two outcome variables from this survey data. First, we examine the effect of FNC on the percentage of respondents in each county that self-identify as Republicans. Second, we look at Americans' latent left-right ideological positions ("ideal points") based on their responses to dozens of policy issue questions. These estimates are based on a two-parameter item response theory (IRT) model (Tausanovitch and Warshaw, 2013). ${ }^{15}$

\footnotetext{
${ }^{15}$ See Clinton, Jackman, and Rivers (2004) and Tausanovitch and Warshaw (2013) for a more detailed background discussion on IRT models. We use updated ideal point estimates from Tausanovitch and Warshaw (2013).
} 


\section{S.1.6. Electoral results and summary statistics}

In Figure S.1 we report a set of time series graphs of the cross-county populationweighted average share for the main outcomes of interest.

Figure S.1: Electoral results by election type and year

(a) Presidential Elections

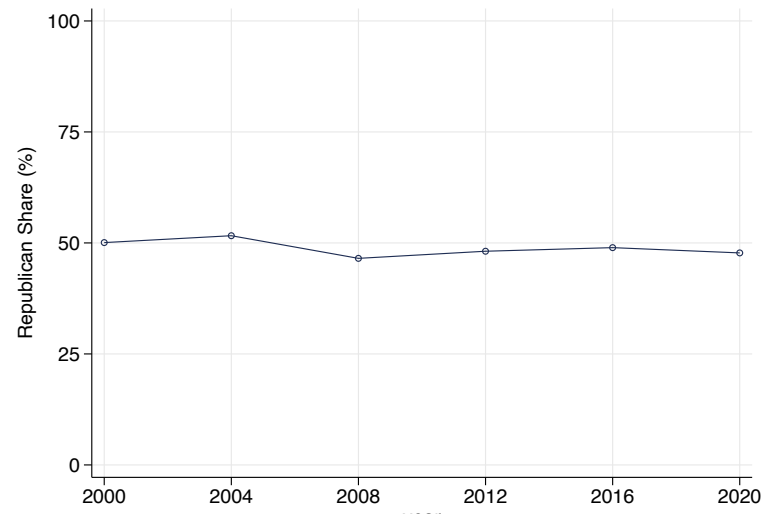

(c) House of Representatives Elections

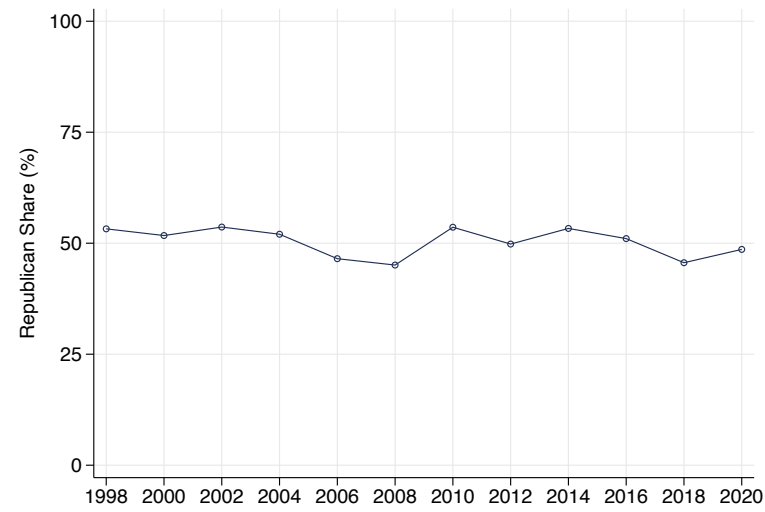

(e) Self-Reported Partisanship

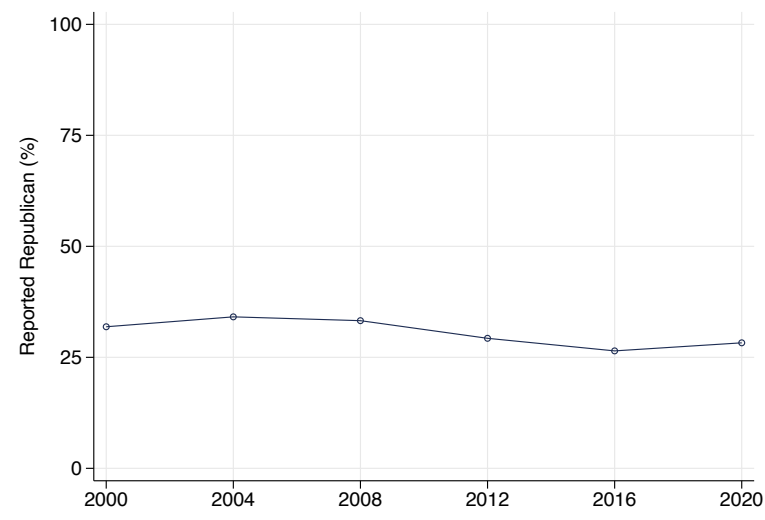

(b) Senate Elections

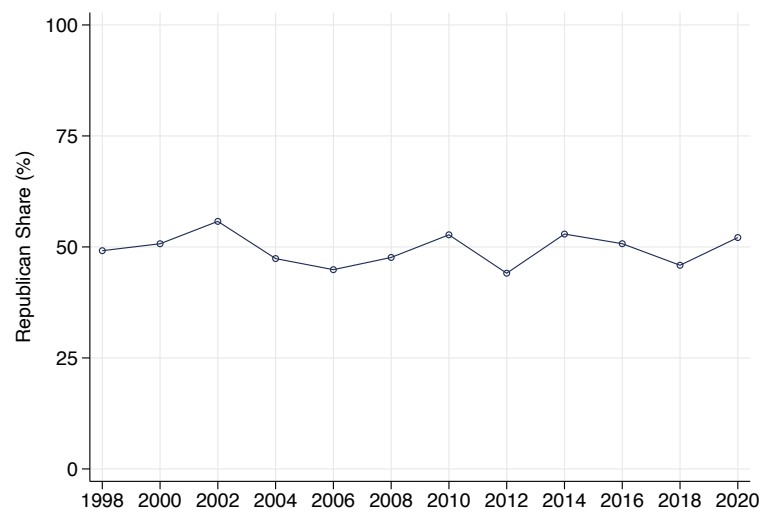

(d) Governor Elections

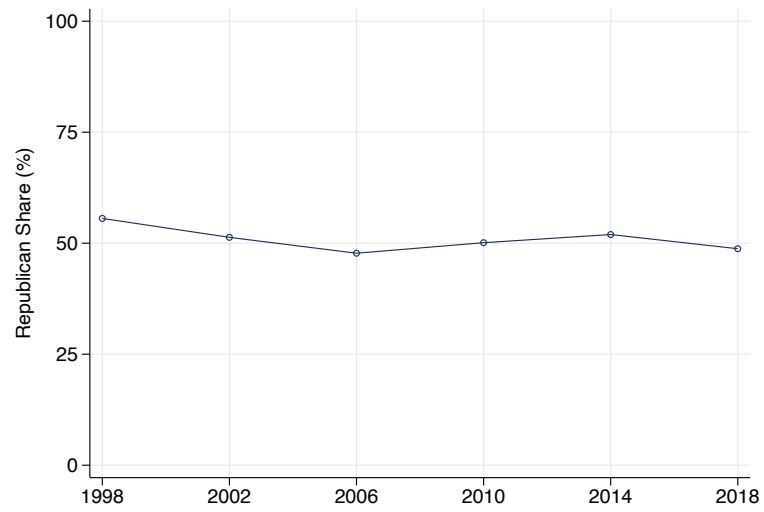

(f) Policy Ideology

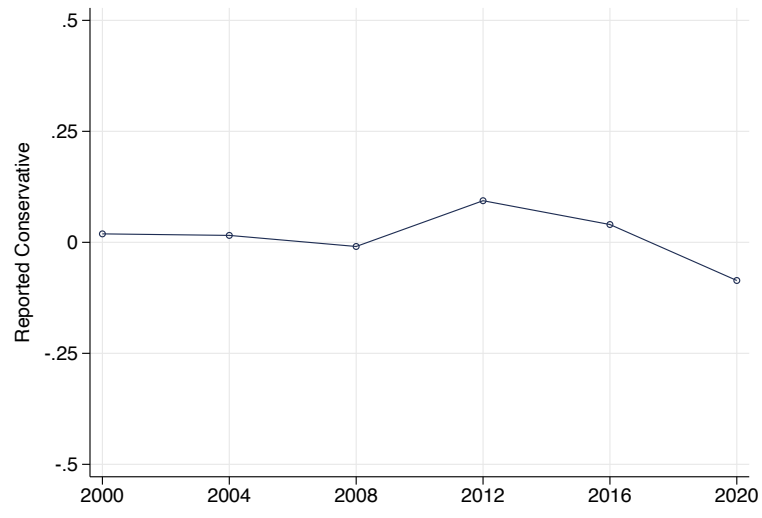


Table S.1: Summary statistics I

\begin{tabular}{|c|c|c|c|c|c|}
\hline Variable & Mean & Std. Dev. & Min & Max & $\mathrm{N}$ \\
\hline \multicolumn{6}{|l|}{ News channels } \\
\hline Position FNC 1998 & 23.421 & 17.018 & 0.747 & 50.608 & 2214 \\
\hline Position FNC 2000 & 28.786 & 17.396 & 1.923 & 54.275 & 2640 \\
\hline Position FNC 2002 & 38.142 & 14.906 & 13.363 & 60.415 & 2966 \\
\hline Position FNC 2004 & 41.565 & 12.686 & 21.281 & 61.068 & 3056 \\
\hline Position FNC 2006 & 41.776 & 11.807 & 22.947 & 59.902 & 3077 \\
\hline Position FNC 2008 & 43.256 & 12.067 & 24.071 & 62.557 & 3084 \\
\hline Position FNC 2010 & 52.66 & 23.422 & 26 & 104.161 & 3088 \\
\hline Position FNC 2012 & 69.174 & 36.284 & 30 & 131.576 & 3090 \\
\hline Position FNC 2014 & 71.126 & 36.673 & 30.694 & 134.232 & 3085 \\
\hline Position FNC 2016 & 74.402 & 38.286 & 31.582 & 139.836 & 3082 \\
\hline Ratings \% CNN 2005 & 0.294 & 0.507 & 0 & 11.6 & 2691 \\
\hline Ratings \% FNC 2005 & 0.560 & 0.948 & 0 & 28.8 & 2776 \\
\hline Ratings \% MSNBC 2005 & 0.06 & 0.143 & 0 & 4.8 & 2691 \\
\hline Ratings \% CNN 2006 & 0.324 & 0.709 & 0 & 23.9 & 2652 \\
\hline Ratings \% FNC 2006 & 0.512 & 0.637 & 0 & 12.2 & 2744 \\
\hline Ratings \% MSNBC 2006 & 0.083 & 0.191 & 0 & 6.75 & 2652 \\
\hline Ratings \% CNN 2008 & 0.433 & 0.831 & 0 & 19.7 & 2647 \\
\hline Ratings \% FNC 2008 & 0.647 & 0.875 & 0 & 21.5 & 2740 \\
\hline Ratings \% MSNBC 2008 & 0.175 & 0.577 & 0 & 26 & 2647 \\
\hline Ratings \% CNN 2020 & 0.383 & 0.631 & 0 & 20.3 & 3039 \\
\hline Ratings \% MSNBC 2020 & 0.537 & 0.835 & 0 & 26.4 & 3039 \\
\hline Ratings \% FNC 2020 & 1.655 & 2.343 & 0 & 67.400 & 3039 \\
\hline Share pop. access to Fox News 1998 & 0.546 & 0.35 & 0 & 1 & 2215 \\
\hline Share pop. access to Fox News 2000 & 0.641 & 0.337 & 0 & 1 & 2640 \\
\hline Share pop. access to Fox News 2002 & 0.786 & 0.268 & 0 & 1 & 2966 \\
\hline Share pop. access to Fox News 2004 & 0.854 & 0.207 & 0 & 1 & 3054 \\
\hline Share pop. access to Fox News 2006 & 0.877 & 0.184 & 0.002 & 1 & 3075 \\
\hline Share pop. access to Fox News 2008 & 0.886 & 0.179 & 0 & 1 & 3083 \\
\hline Share pop. access to Fox News 2010 & 0.9 & 0.172 & 0 & 1 & 3087 \\
\hline Share pop. access to Fox News 2012 & 0.919 & 0.159 & 0 & 1 & 3089 \\
\hline Share pop. access to Fox News 2014 & 0.921 & 0.157 & 0 & 1 & 3084 \\
\hline Share pop. access to Fox News 2016 & 0.92 & 0.164 & 0 & 1 & 3081 \\
\hline \multicolumn{6}{|l|}{ Demographic } \\
\hline Population & 100481.877 & 317608.202 & 80 & 9818535 & 3039 \\
\hline Area & 511.104 & 664.694 & 1.553 & 9309.787 & 3039 \\
\hline Population density & 187.73 & 919.58 & 0.129 & 33886.035 & 3039 \\
\hline Vote share Republican cand. pres. election 1996 & 50.469 & 11.733 & 10.696 & 88.208 & 3108 \\
\hline Age imbalance & 1.702 & 0.226 & 1.09 & 4 & 3039 \\
\hline$\%$ Food stamps & 0.126 & 0.06 & 0 & 0.431 & 3039 \\
\hline$\%$ Male & 0.499 & 0.021 & 0.438 & 0.719 & 3039 \\
\hline$\%$ White & 0.833 & 0.161 & 0.121 & 0.991 & 3039 \\
\hline$\%$ Black & 0.089 & 0.144 & 0 & 0.851 & 3039 \\
\hline$\%$ Hispanic & 0.081 & 0.127 & 0.003 & 0.958 & 3039 \\
\hline$\%$ Asian & 0.011 & 0.023 & 0 & 0.439 & 3039 \\
\hline$\%$ Urban & 0.185 & 0.328 & 0 & 1 & 3039 \\
\hline$\%$ Rural & 0.587 & 0.304 & 0 & 1 & 3039 \\
\hline$\%$ College & 0.192 & 0.085 & 0.054 & 0.706 & 3039 \\
\hline
\end{tabular}




\section{S.2. Instrument validity}

\section{S.2.1. First stage}

Figure S.2 shows a binscatter of first stage regression of Fox News Rating on the instrument Fox News channel position. Ratings used are 2005, 2006, 2008 and 2020, at the county level and standardized. We use 2005 ratings in place of 2004 ratings. For each year of elections we use the corresponding year's channel position, except for 2020 (2016 positions). Channel positions are also standardized. We include state-year fixed effects, ratings controls for CNN and MSNBC, and control for the share of the population in the county that can receive $\mathrm{FNC}$ in that year. We further control for socio-demographic characteristic of the county (2010 census), as described in Section 3, and 1996 presidential elections results. Standard errors are clustered by state.

Figure S.2: Instrument relevance

(a) First stage coefficients

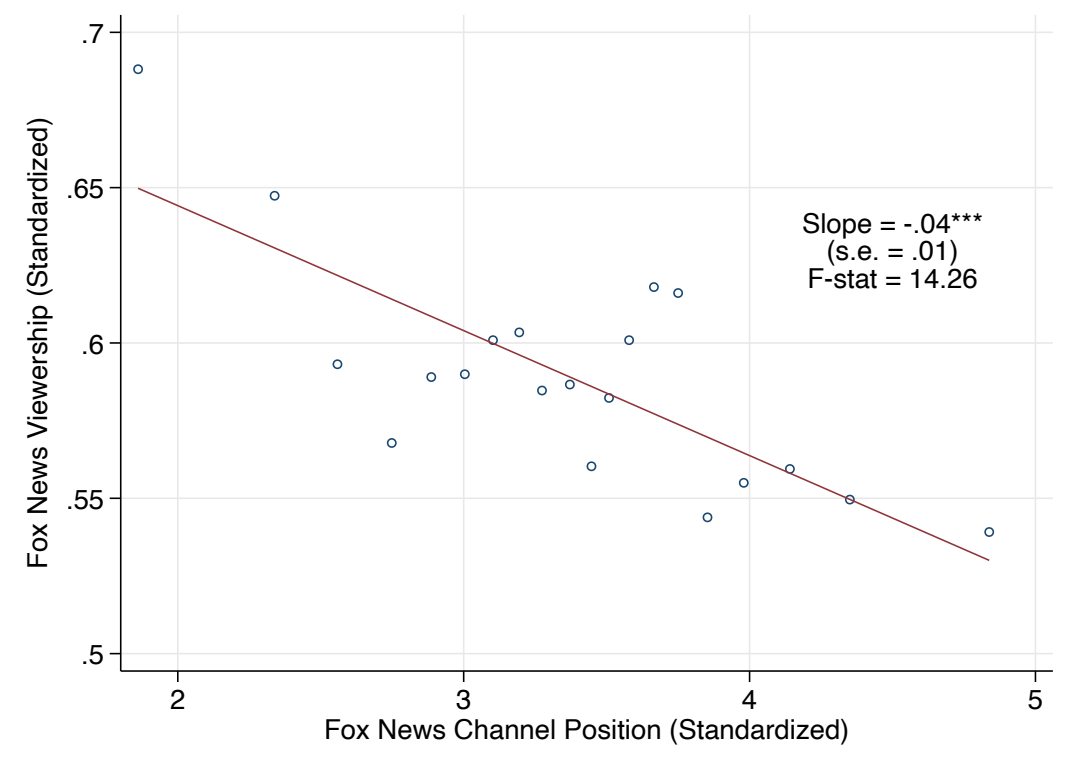

From the first stage estimation we see that a decrease in the channel position (there-

fore more likely to be accessed when zapping) of one standard deviation, roughly 29 positions, is associated with an increase in viewership of $4 \%$ of a standard deviation, 
roughly 0.056 ratings points, ${ }^{16}$ or 7 minutes per week of (additional) FNC viewership for the average household, a $7 \%$ increase above the mean viewership duration.

\section{S.2.2. Instrument placebo tests}

Table S.2 provides a number of tests to assess the exogeneity of the instrument. Specifically, we want to exclude the possibility that there is a potential endogenous manipulation of the channel numbering applied by cable system provider such us FNC channel position is systematically correlated with demographic characteristics that could predict either viewership or voting behavior. First, we estimate a model where the outcome variable is a linear prediction for ratings based on socio-demographic characteristics and the right-hand-side variable is FNC channel position. Column (1) shows that channel position is not correlated with demographics that would otherwise predict high ratings. Second, we apply a similar procedure but analyzing socio-demographic characteristics that predict electoral outcomes. Columns (2-3) show that channel position is not correlated with vote-share-relevant demographics. Third, column (4) shows that channel position (earliest available, 1998) is not correlated with Republican vote share in 1996 presidential elections (before the introduction of FNC). Ratings used are 2005, 2006, 2008 and 2020, at the county level and standardized by standard deviation. We use 2005 ratings in place of 2004 ratings. For each year of elections we use the corresponding year's channel position, except for 2020 (2016 positions). Channel positions are standardized by their standard deviation. All regressions control for the share of county population living in zipcodes with access to the network and with state-year fixed effects. Robust standard errors clustered at the state level are in parentheses.

\footnotetext{
${ }^{16}$ With one rating point corresponding to roughly 108 minutes per week of Fox News viewership for the average household (Martin and Yurukoglu, 2017).
} 
Table S.2: Instrument Placebo Tests

\begin{tabular}{lcccc}
\hline & Predicted ratings & $\begin{array}{c}\text { Predicted voting } \\
\text { (Presidential) }\end{array}$ & $\begin{array}{c}\text { Predicted voting } \\
\text { (House) }\end{array}$ & 1996 Rep. Votes \\
\hline FNC position & -0.003 & 0.0003 & -0.001 & 0.006 \\
& $(0.003)$ & $(.004)$ & $(.003)$ & .005 \\
Observations & 11,108 & 11,648 & 9,032 & 2,183 \\
$R^{2}$ & 0.49 & 0.34 & 0.37 & 0.7246 \\
\hline Note: Robust standard errors clustered at the state level are in parentheses: ${ }^{+} p<0.10,{ }^{*} p<0.05$, \\
$* * p<0.01,{ }^{* * *} p<0.001$.
\end{tabular}




\section{S.2.3. Fox News availability in the counties}

Figure S.3 shows a time series of the cross-county average share of the population with access to Fox News, computed as the share of county population living in zipcodes with access to the network, for the years of availability of the Channel Position instrument (1998-2016).

Figure S.3: Share of Population with Access to Fox News

(a)

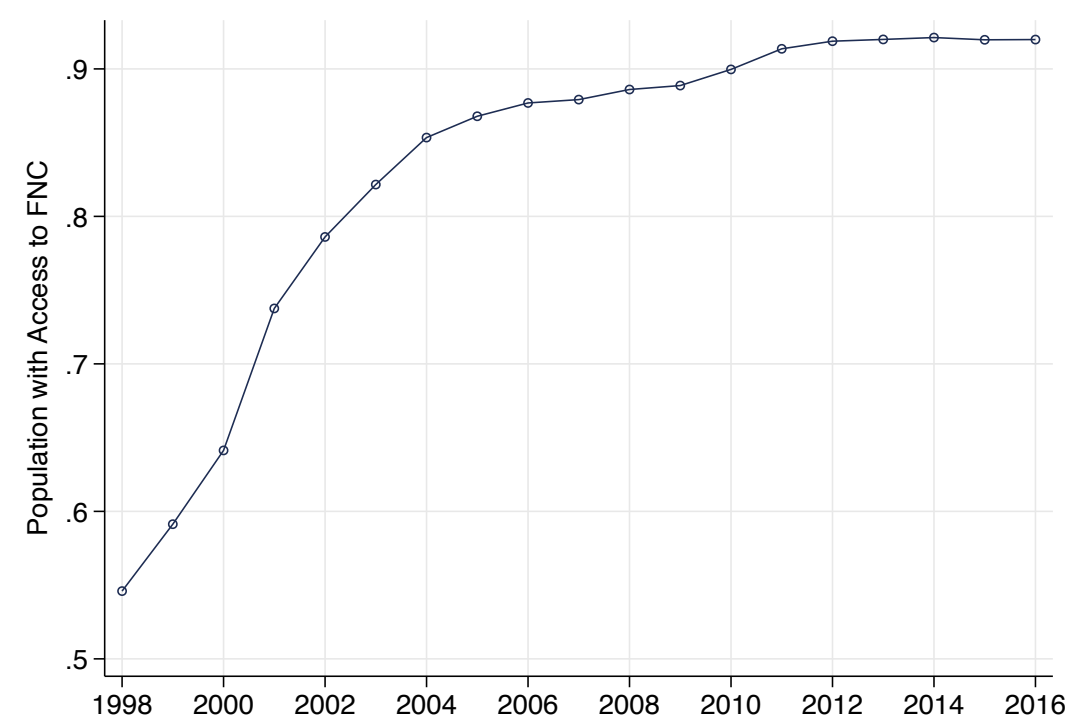




\section{S.3. Tables for main-text results}

Table S.3 reports coefficient estimates for presidential elections outcomes (specific year defined in column header) using Two Stages Least Squares Estimation using with channel position as instrument for FNC viewership. We include state-year fixed effects, ratings controls for CNN and MSNBC, and controls for the share of zipcodes in the county that can receive FNC in that year. We furthermore control for socio-demographic characteristic of the county (2010 census) and 1996 presidential elections results. In the analysis we use 2005 ratings for ratings pre-2005 and an interpolation between 2008 and 2020 ratings for ratings of 2009-2019.

Table S.3: Presidential election 2SLS results

\begin{tabular}{lcccccc}
\hline & \multicolumn{5}{c}{ Elections year } \\
\cline { 2 - 7 } & 2000 & 2004 & 2008 & 2012 & 2016 & 2020 \\
\hline FNC viewership & -0.728 & 3.094 & 10.846 & 45.525 & $26.415^{+}$ & $18.511^{*}$ \\
& $(2.498)$ & $(3.925)$ & $(8.134)$ & $(45.076)$ & $(13.885)$ & $(8.646)$ \\
CNN viewership & -0.262 & $-0.658^{+}$ & -0.751 & -2.860 & -0.808 & -0.384 \\
& $(0.209)$ & $(0.342)$ & $(0.792)$ & $(3.170)$ & $(0.814)$ & $(0.406)$ \\
MSNBC viewership & -0.231 & -0.470 & -0.250 & -1.498 & $-2.084^{*}$ & $-1.401^{* *}$ \\
& $(0.197)$ & $(0.329)$ & $(0.276)$ & $(1.781)$ & $(0.945)$ & $(0.486)$ \\
R $^{2}$ & 0.974 & 0.934 & 0.746 & -0.500 & 0.669 & 0.690 \\
N observations & 2310 & 2620 & 2597 & 2600 & 2586 & 3029 \\
\hline
\end{tabular}

Note: Robust standard errors clustered at the state level are in parentheses: ${ }^{+} p<0.10,{ }^{*}$ $p<0.05,{ }^{* *} p<0.01,{ }^{* * *} p<0.001$. 
Table S.4 reports coefficient estimates for all the main results reported in figures in the main text. Each entry is a separate RF regression, where the year considered is the one reported in the first column, while the column headings define the outcome variable of interest.

Table S.4: Main results

\begin{tabular}{|c|c|c|c|c|c|c|c|}
\hline \multicolumn{5}{|c|}{ Election Results } & \multicolumn{3}{|c|}{ Survey } \\
\hline Year & Pres. & House & Senate & Governor & Year & Partisanship & Ideology \\
\hline 1998 & & $\begin{array}{c}0.91 \\
(1.127)\end{array}$ & $\begin{array}{c}0.441 \\
(0.425)\end{array}$ & $\begin{array}{l}-0.167 \\
(0.331)\end{array}$ & 1998 & & \\
\hline 2000 & $\begin{array}{l}-0.051 \\
(2.498)\end{array}$ & $\begin{array}{l}-0.539 \\
(1.379)\end{array}$ & $\begin{array}{l}-0.139 \\
(0.547)\end{array}$ & & 2000 & $\begin{array}{l}-0.446 \\
(0.449)\end{array}$ & $\begin{array}{c}0.010 \\
(0.009)\end{array}$ \\
\hline 2002 & & $\begin{array}{c}-0.564 \\
(0.684)\end{array}$ & $\begin{array}{c}0.087 \\
(0.211)\end{array}$ & $\begin{array}{c}0.046 \\
(0.282)\end{array}$ & 2002 & & \\
\hline 2004 & $\begin{array}{c}0.146 \\
(0.163)\end{array}$ & $\begin{array}{l}-0.224 \\
(0.508)\end{array}$ & $\begin{array}{c}-0.092 \\
(0.159)\end{array}$ & & 2004 & $\begin{array}{l}-0.294 \\
(0.268)\end{array}$ & $\begin{array}{l}0.011^{*} \\
(0.005)\end{array}$ \\
\hline 2006 & & $\begin{array}{c}0.100 \\
(0.436)\end{array}$ & $\begin{array}{c}0.465^{*} \\
(0.211)\end{array}$ & $\begin{array}{c}0.051 \\
(0.204)\end{array}$ & & & \\
\hline 2008 & $\begin{array}{c}0.367 \\
(0.246)\end{array}$ & $\begin{array}{c}0.005 \\
(0.526)\end{array}$ & $\begin{array}{c}0.419 \\
(0.353)\end{array}$ & & $\begin{array}{c}2006 \\
-2008\end{array}$ & $\begin{array}{l}0.651^{+} \\
(0.386)\end{array}$ & $\begin{array}{c}0.010 \\
(0.008)\end{array}$ \\
\hline 2010 & & $\begin{array}{c}-0.11 \\
(0.547)\end{array}$ & $\begin{array}{c}0.134 \\
(0.224)\end{array}$ & $\begin{array}{c}0.223 \\
(0.249)\end{array}$ & & & \\
\hline 2012 & $\begin{array}{c}0.506^{*} \\
(0.230)\end{array}$ & $\begin{array}{c}0.583 \\
(0.471)\end{array}$ & $\begin{array}{c}0.298 \\
(0.245)\end{array}$ & & $\begin{array}{c}2009 \\
-2012\end{array}$ & $\begin{array}{l}0.777^{*} \\
(0.355)\end{array}$ & $\begin{array}{c}0.003 \\
(0.006)\end{array}$ \\
\hline 2014 & & $\begin{array}{c}0.845 \\
(0.878)\end{array}$ & $\begin{array}{l}0.509^{+} \\
(0.294)\end{array}$ & $\begin{array}{c}0.309 \\
(0.325)\end{array}$ & & & \\
\hline 2016 & $\begin{array}{c}0.614^{* *} \\
(0.185)\end{array}$ & $\begin{array}{c}0.707 \\
(0.496)\end{array}$ & $\begin{array}{c}0.593^{*} \\
(0.241)\end{array}$ & & $\begin{array}{c}2013 \\
-2016\end{array}$ & $\begin{array}{l}0.727^{+} \\
(0.367)\end{array}$ & $\begin{array}{l}0.012^{+} \\
(0.007)\end{array}$ \\
\hline 2018 & & $\begin{array}{c}1.568^{* * *} \\
(0.424)\end{array}$ & $\begin{array}{c}0.777^{* *} \\
(0.239)\end{array}$ & $\begin{array}{c}0.588^{* *} \\
(0.207)\end{array}$ & & & \\
\hline 2020 & $\begin{array}{c}0.623^{* *} \\
(0.200)\end{array}$ & $\begin{array}{c}1.103^{* * *} \\
(0.258)\end{array}$ & $\begin{array}{l}0.559^{*} \\
(0.249)\end{array}$ & & $\begin{array}{c}2017 \\
-2020\end{array}$ & $\begin{array}{l}0.555^{+} \\
(0.301)\end{array}$ & $\begin{array}{c}0.009 \\
(0.009)\end{array}$ \\
\hline
\end{tabular}

Note: Robust standard errors clustered at the state level are in parentheses: ${ }^{+} p<0.10,{ }^{*}$ $p<0.05,{ }^{* *} p<0.01,{ }^{* * *} p<0.001$. 


\section{S.4. Additional down-ballot election and survey results}

Figure S.4 displays coefficient estimates from reduced form regressions for a further set of down-ballot statewide races. Results hint at a positive effect of Fox News on Attorney General (panel a) and Treasurer (panel b) races, though mostly not significant, and no effect on Secretary of State (panel c) races.

Figure S.4: Results for Other Down-Ballot Elections

(a) Attorney General

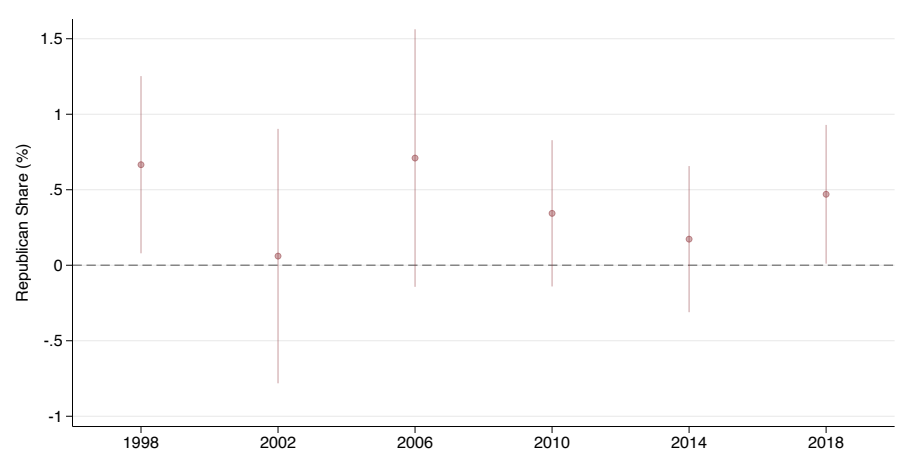

(b) State Treasurer

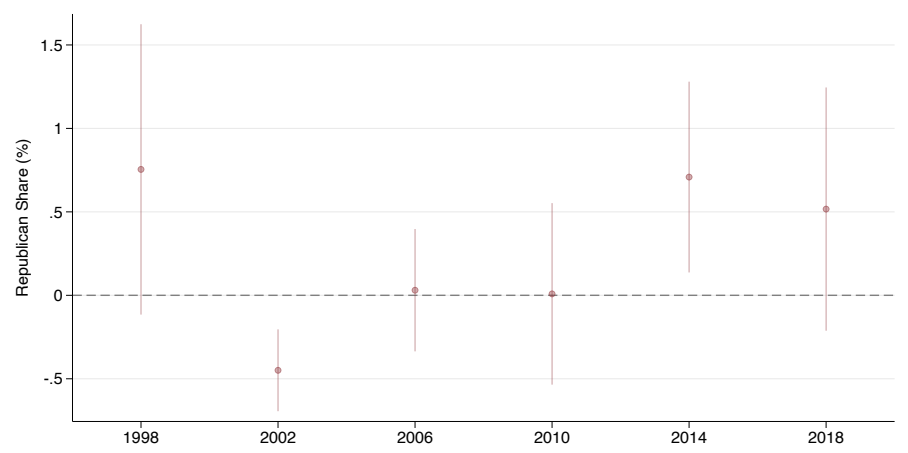

(c) Secretary of State

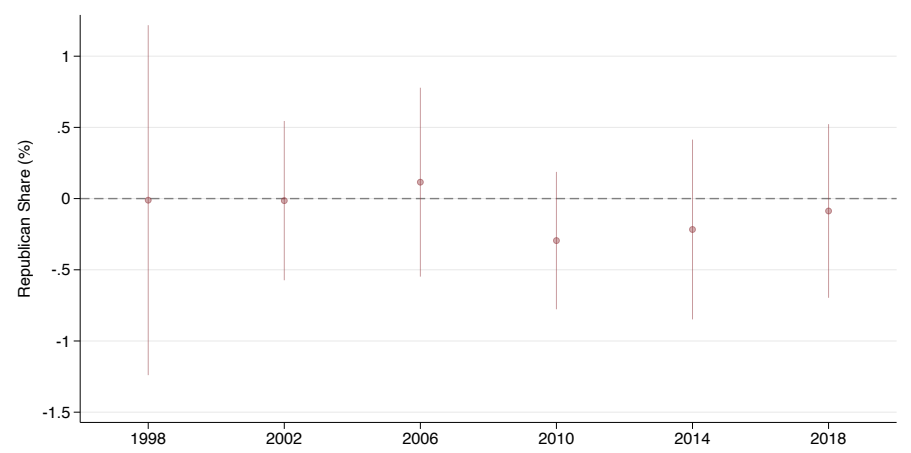


Figure S.5 displays reduced form estimates using an additional survey-based outcome: symbolic (5-point) ideology. The results are similar to the ideology measure shown in the main text.

Figure S.5: Alternative ideology measure

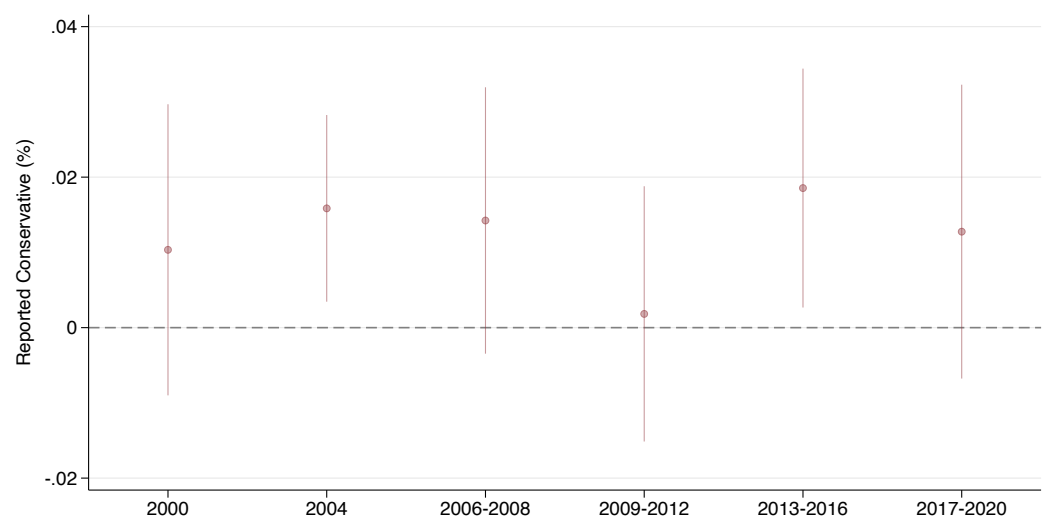




\section{S.5. Robustness checks}

We conduct a series of supporting analyses to better understand the results. First, we re-run all the analyses for the main elections outcomes using a Two Stages Least Squares Estimation (Figure S.6) using the channel position as instrument for viewership, with similar results. Table S.3 shows in more detail the estimates for the presidential elections 2SLS, and the relative CNN and MSNBC controls. ${ }^{17}$ We then run an OLS regression of viewership's association with the outcomes (Figure S.7), and find a positive correlation between higher Fox News ratings and voting Republican.

Next, we run checks looking at the sensitivity of estimates to the presence of specific sets of controls. In Figure S.11, we replicate our main results by running a set of reduced-form regressions, each time excluding a different set of the socio-demographic and political controls: age controls, race controls, urban-rural density controls, education controls, occupation controls. The results are robust. In Figure S.12 we see how our extensive set of controls helps us to pin down the magnitude of the positive effect of Fox News. It is worth noting that our main specification set of controls doesn't work as well with interpolated ratings in the 2SLS and including additional controls (more education controls and extensive occupation controls) doesn't affect our reduced form estimates. Results are also robust to dropping sample weights (Figure S.13).

In Figure S.10, we explore heterogeneity by pre-treatment partisanship or early surveyreported measures of partisanship and ideology. We find a slightly greater magnitude of effects for democratic/liberal counties, though the difference between samples is not statistically significant.

Next, we perform a number of placebo tests. First, the estimates for the first year of activity of Fox News (1996) are not significant (Figure S.9a). We show this as well in Table S.2, column 4. Second, controlling for presidential elections results for 1988, 1992, 1996 or any combination

\footnotetext{
${ }^{17}$ In the context of the 2SLS analysis we use 2005 ratings for ratings pre-2005 and an interpolation between 2008 and 2020 ratings for ratings of 2009-2019. Results are robust to alternative input methods, as using the average of the ratings or replacing missing ratings with the earliest available ones. Interpolated years show noisier estimates.
} 
of these, doesn't affect results (S.9b).

We then focus our attention on the effect of CNN and MSNBC. These networks show no statistically significant effect in the reduced form estimates in Figure S.8, nor when included as ratings (Table S.3). We note that the first stage estimation for those channels is weaker.

Finally, we run some tests on the sample. We conduct a perturbation test regressing our extended specification 49 times, each time dropping the data for one state (Figure S.14) confirming that results are not driven by any specific outlier state, though the smaller sample size affects the first stage. 


\section{S.5.1. Ordinary least squares and two stages least squares of main regressions}

Figure S.6 reports Two Stages Least Squares Estimation for the main electoral results President in panel (a), Senate in panel (b), House in panel (c) and Governor in panel (d) using the channel position as instrument for viewership. We use 2005 ratings for ratings pre2005 and an interpolation between 2008 and 2020 ratings for ratings of 2009-2019. Results are robust to using the average of the ratings, replacing missing ratings with the earliest available ones, instead. Interpolated years $(*)$ show noisier estimates. Governor elections results are averaged with previous three years elections, except for 1998, that includes only 1998 elections. The estimates are coherent with our main results in Figure 3.

Figure S.6: Main Elections Results: 2SLS

(a) Presidential Elections

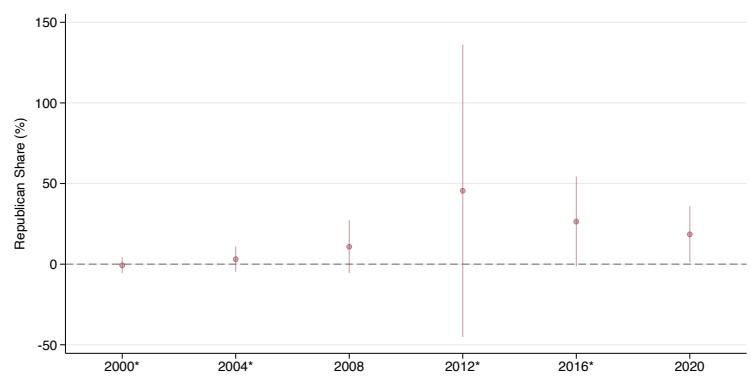

(c) House of Representatives Elections

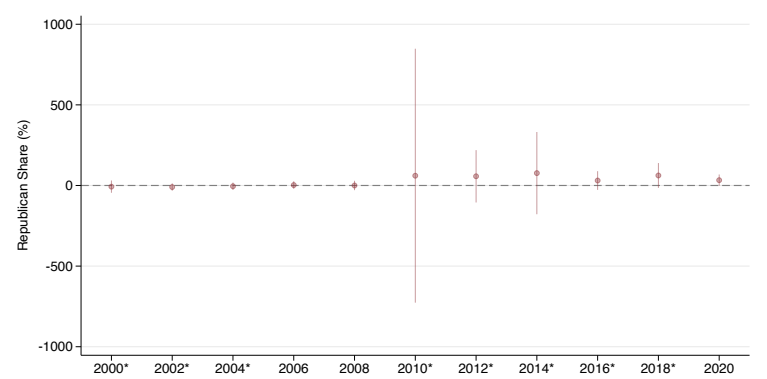

(b) Senate Elections

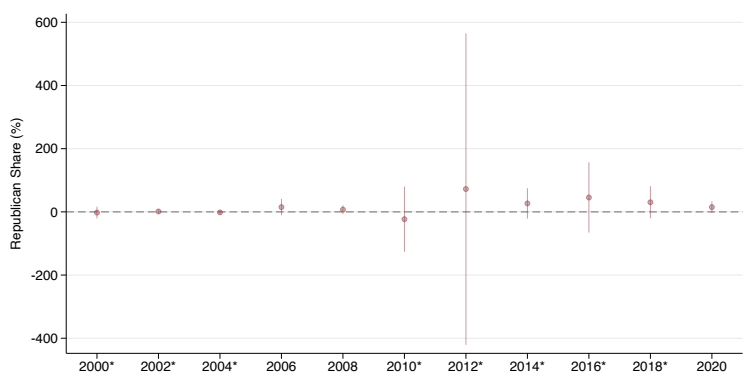

(d) Governor elections

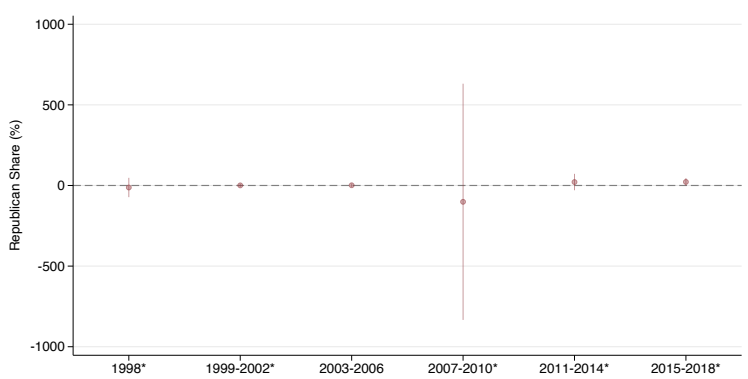


Figure S.7 reports OLS estimates for the main electoral results - President in panel (a), Senate in panel (b), House in panel (c) and Governor in panel (d). As the main regressor, we use 2005 ratings for pre-2005 years and an interpolation between 2008 and 2020 ratings for 2009-2019 (*).

The OLS analysis, simply regressing Fox News viewership on the outcome (with the same controls as in the reduced form), shows the positive correlation between watching Fox News and voting Republican. However, such estimates are likely to be biased, due to the endogeneity of viewing decisions. As mentioned in the main text, places that have a pre-existing conservative slant will have a stronger preference to watch FNC, so correlations between political choices and Fox viewership may be confounded.

Figure S.7: Main Elections Results: OLS

(a) Presidential Elections

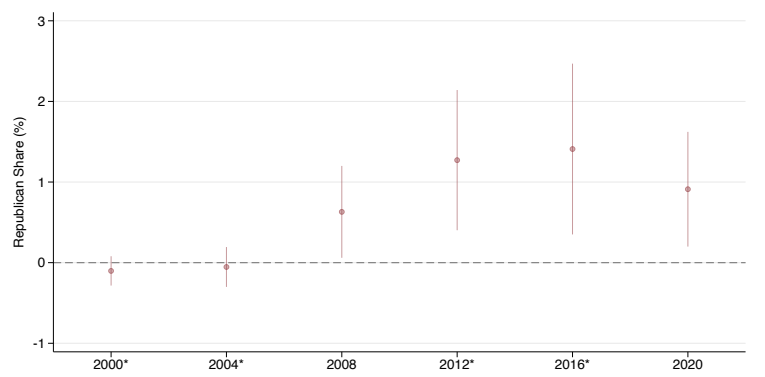

(c) House of Representatives Elections

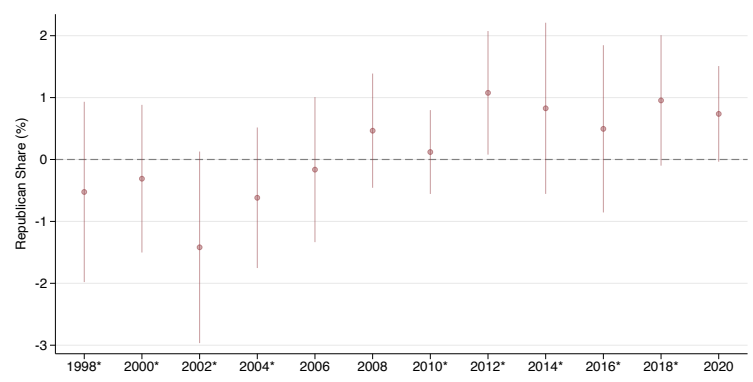

(b) Senate Elections

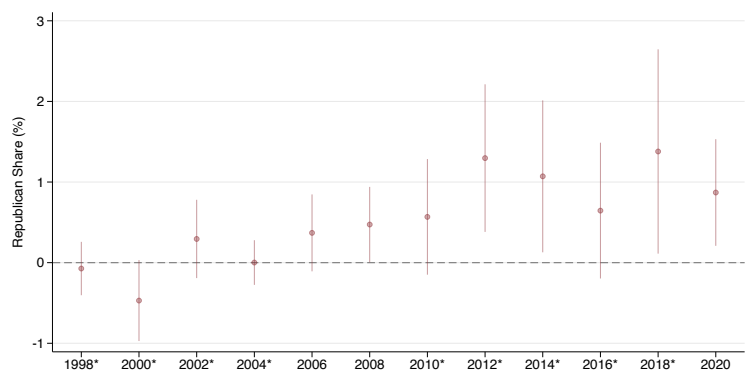

(d) Governor elections

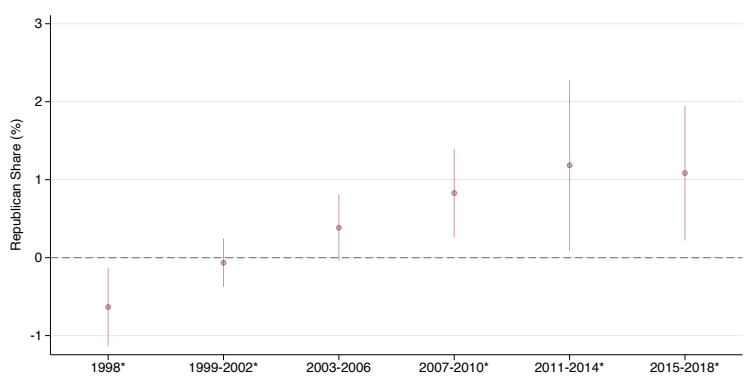




\section{S.5.2. Other networks}

Figure S.8 shows that the reduced form presidential electoral results are robust to including controls for the channel positions of the other networks ${ }^{18}$ (and ratings, as in our main specification). With the caveat of a weaker first stage for those networks, estimates for CNN and MSNBC are mostly negative and not statistically significant. The exception is a positive effect for CNN in 2004 elections, which is perhaps not surprising given that CNN was relatively supportive of George W. Bush and the War in Iraq.

Figure S.8: Effects of other networks

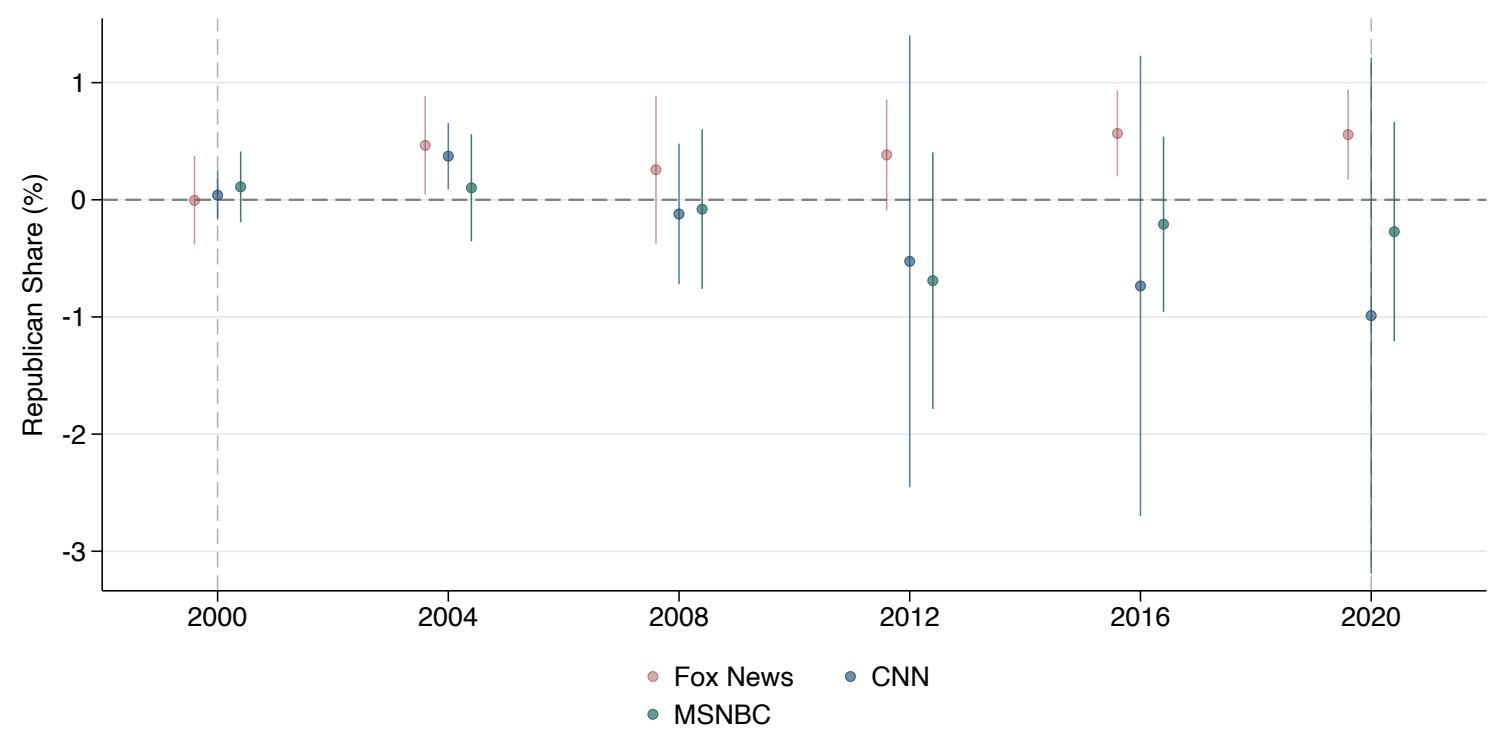

\footnotetext{
${ }^{18}$ Fox News channel position is netted out the other networks' channels.
} 


\section{S.5.3. Pre-treatment placebo checks}

Figure S.9 displays further robustness checks by showing that electoral results from before the introduction of FNC do not correlate with our instrument and that they do not alter our results if included as controls to our baseline specification. Panel (a) shows reduced form regressions of all years Fox News channel positions on 1996 Presidential Results. Panel (b) reports the reduced form regression including as controls separately and combined 1988, 1992, and 1996 presidential elections results.

Figure S.9: Pre-treatment placebo checks

(a) Instrument correlation with 1996 Presidential Results

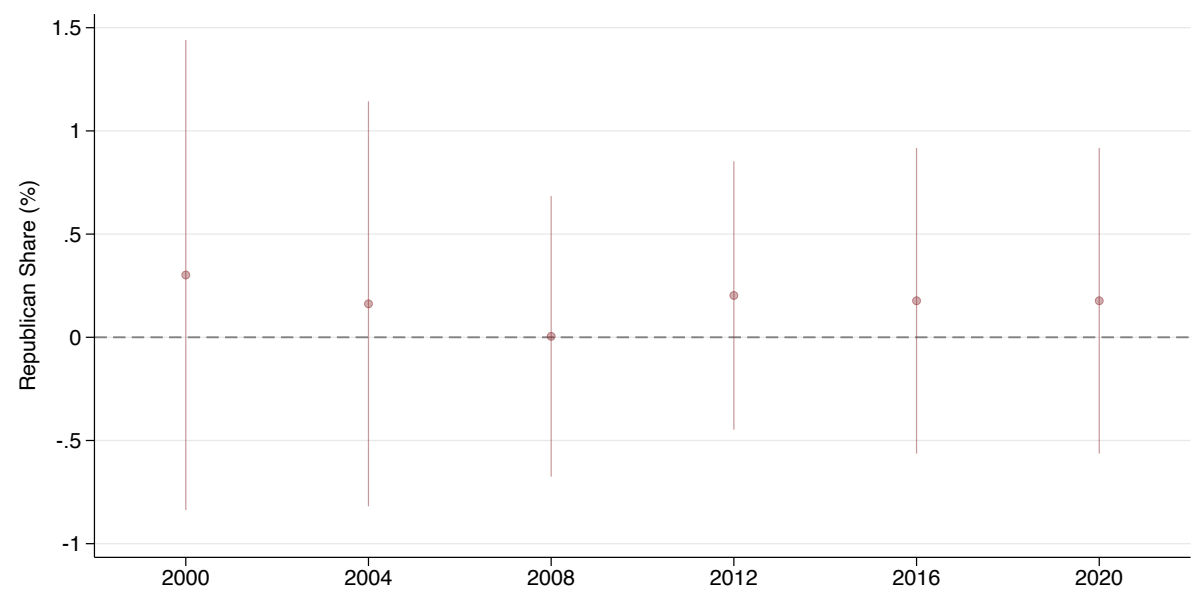

(b) Further pre-treatment elections controls

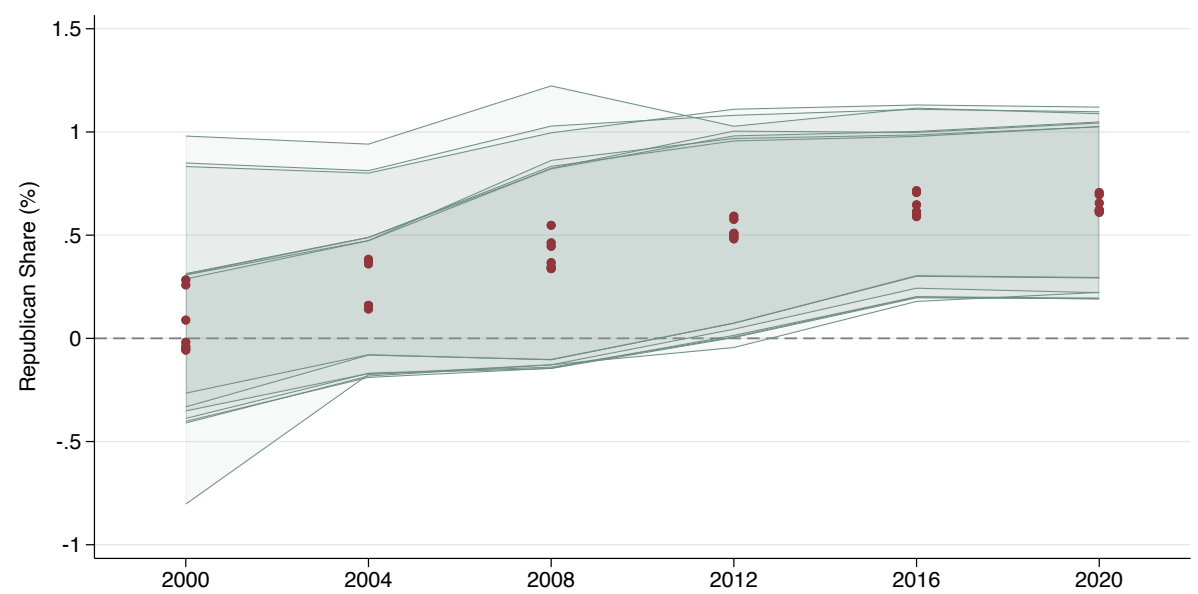




\section{S.5.4. Heterogeneity by partisanship and ideology}

Figure S.10 shows reduced form (RF) estimates for our presidential electoral results splitting the sample according to partisanship or ideology in the early years of Fox News. These checks hint at a stronger effect for Democrat counties, though the estimates between the subsamples are not statistically different from each other.

To the extent that Fox News influences Democratic areas more than Republican areas, that would be consistent with DellaVigna and Kaplan (2007, 1217), who find that "Fox News had the largest impact in Democratic districts" in the 2000 presidential election. Ecological inference problems, however, make it difficult to extrapolate implications for heterogeneity among individual voters. Indeed, Hopkins and Ladd (2014) find stronger effects of FNC among Republicans in the 2000 National Annenberg Election Survey. Future work could focus more on heterogeneity in the effect of partisan media across groups of voters. 
Figure S.10: Presidential elections results

Panel (1) - Splitting by 1998 presidential elections results

(a) Democratic Counties

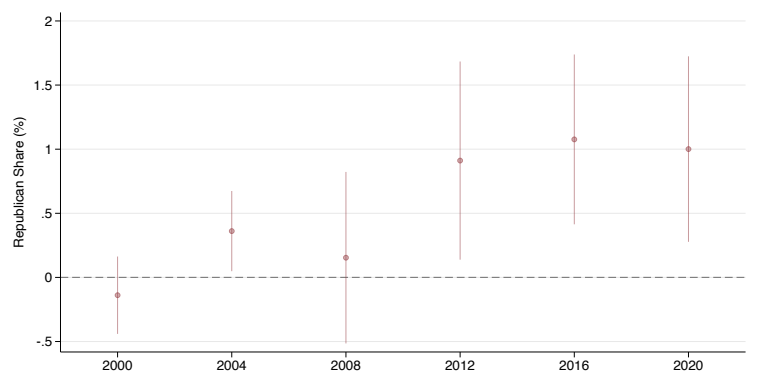

(b) Republican Counties

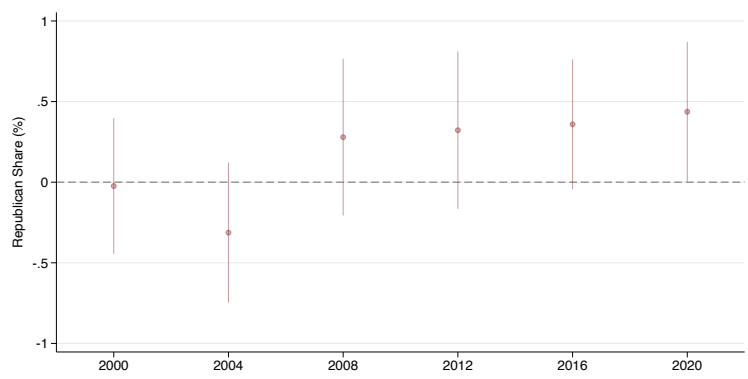

Panel (2) - Splitting by surveyed 2000 median partisanship

(d) Republican Counties
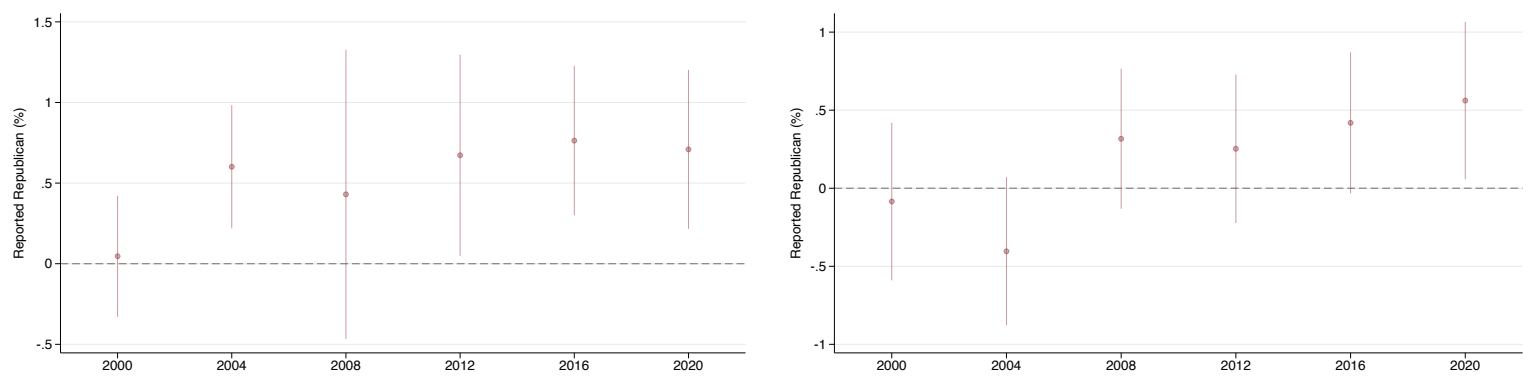

Panel (3) - Splitting by surveyed 2000 median ideology

(e) Liberal Counties

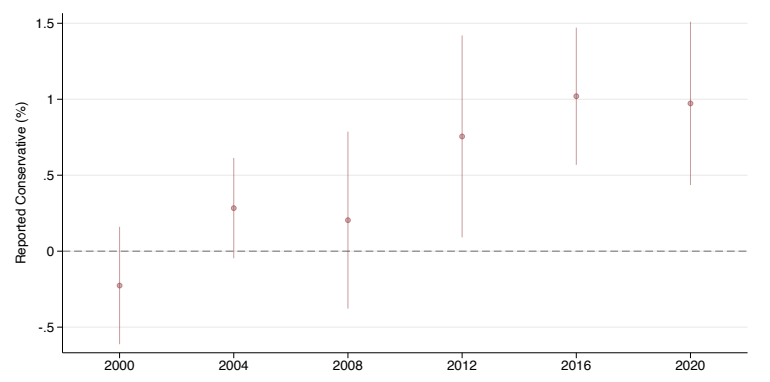

(f) Conservative Counties

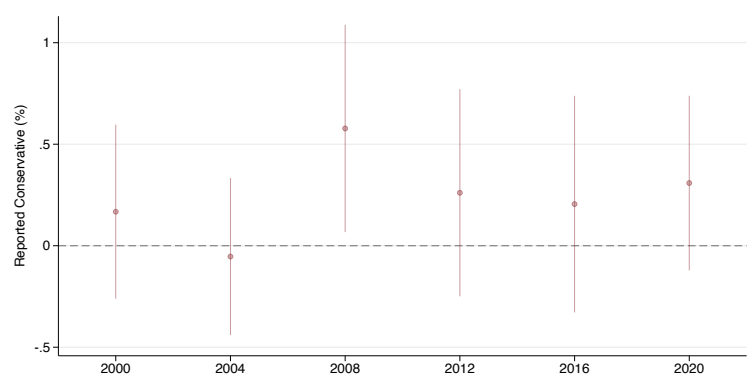




\section{S.5.5. Specification checks}

Figure S.11 shows reduced form (RF) estimates for our main electoral results dropping various sets of controls. We run here a multitest, by election, dropping each time a set of controls: age controls, race controls, urban-rural density controls, education controls, occupation controls. In red are the estimates for the different control sets, and in green, the $95 \%$ confidence intervals. This shows the results are robust to variation in the precise controls we use.

Figure S.11: Main Elections Results, Robustness to dropping groups of controls (RF)

(a) Presidential Elections

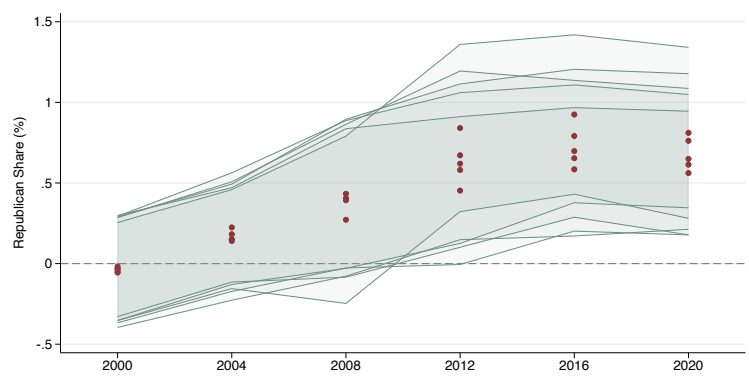

(c) House of Representatives Elections

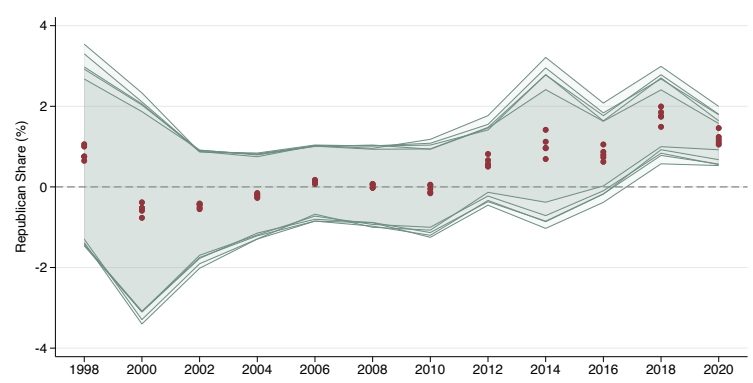

(b) Senate Elections

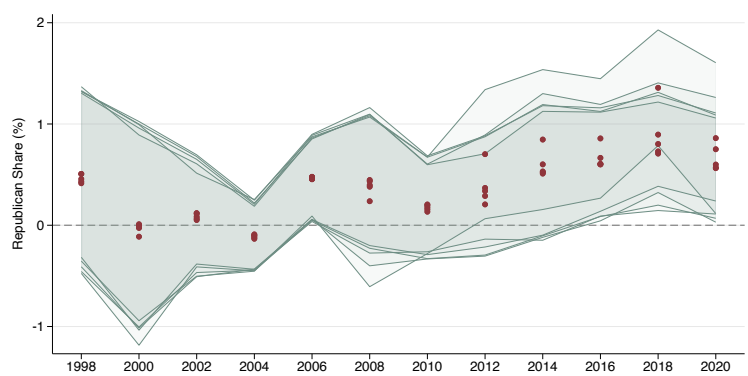

(d) Governor elections

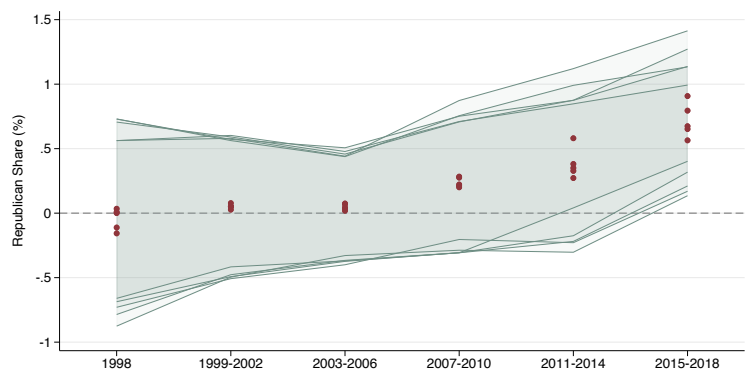


Figure S.12 shows further robustness checks for our main results using additional/less sets of controls. Panel (a) shows results for the effect of Fox News on Presidential Elections, with a reduced set of controls: results are consistent, but interpoled ratings (2012 and 2016) appear noisier. Panel (b) shows how controls help pin down the effect of Fox News, including further education controls (percentage of population with no high school degree and percentage of population with high school as higher education) and extensive occupation controls, produces similar estimates as our main specification.

Figure S.12: Presidential Elections - Variations to the control set

(a) Two Stages Least Squares

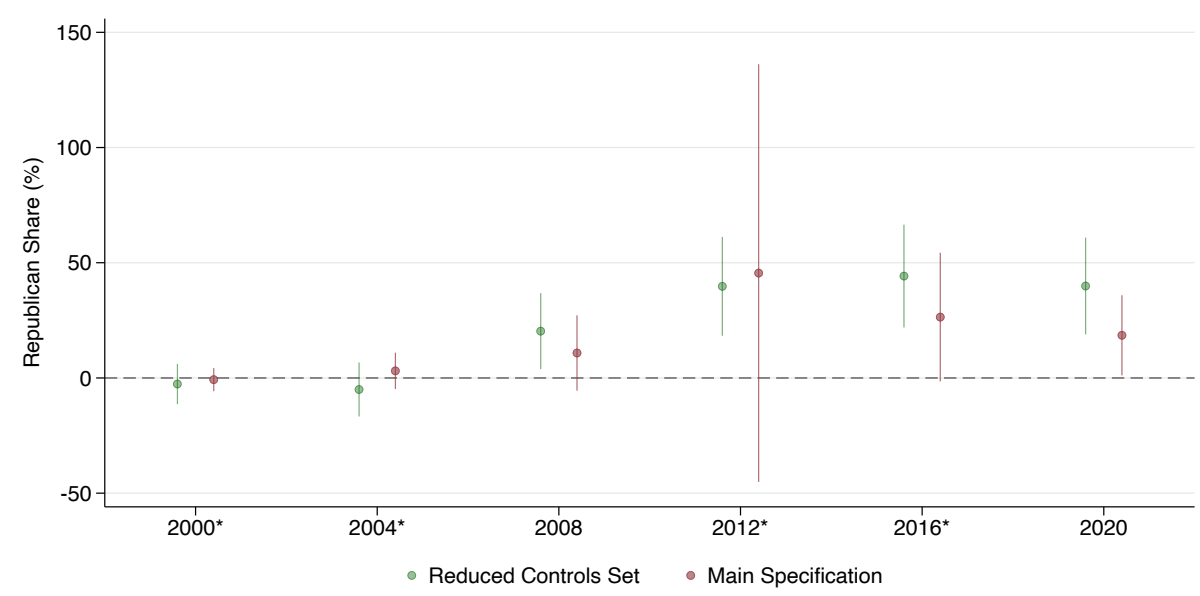

(b) Reduced Form

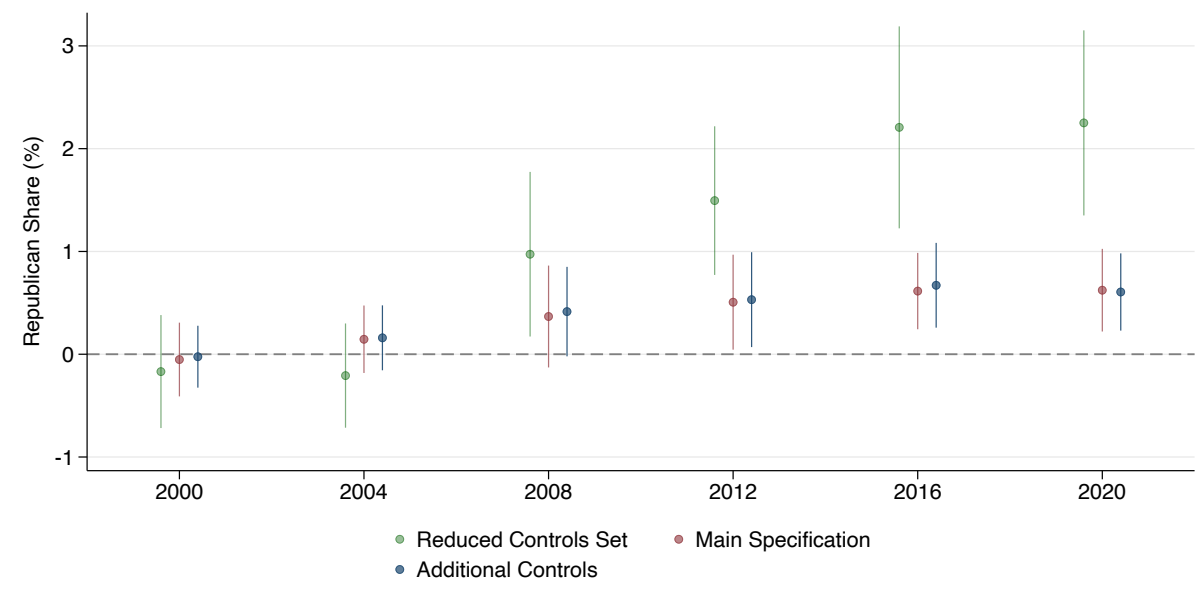


Figure S.13 shows reduced form (RF) estimates for our main electoral results without sample weighting. Despite the First Stage estimation without weighting being poorer, estimates appear to be robust, though slightly smaller in magnitude.

Figure S.13: Main Elections Results, without Sample Weights (RF)

(a) Presidential Elections

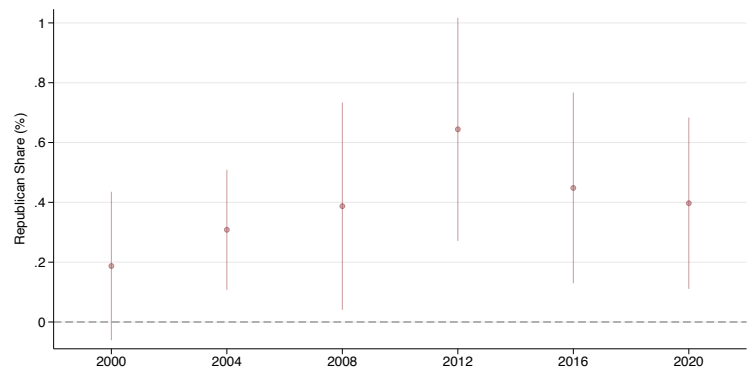

(c) House of Representatives Elections

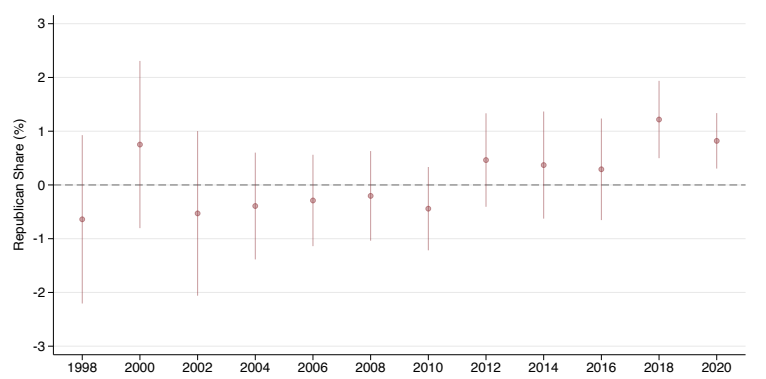

(b) Senate Elections

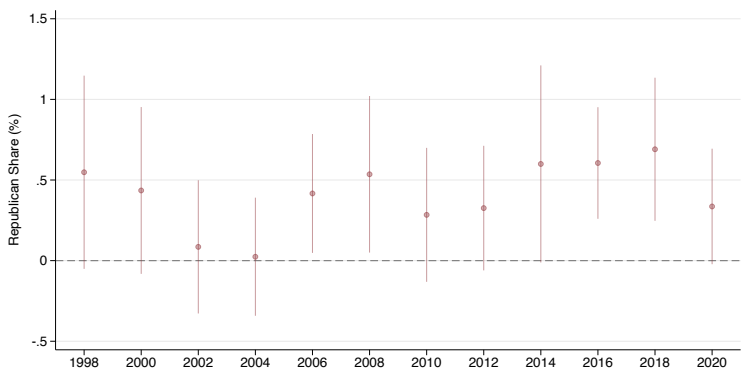

(d) Governor elections

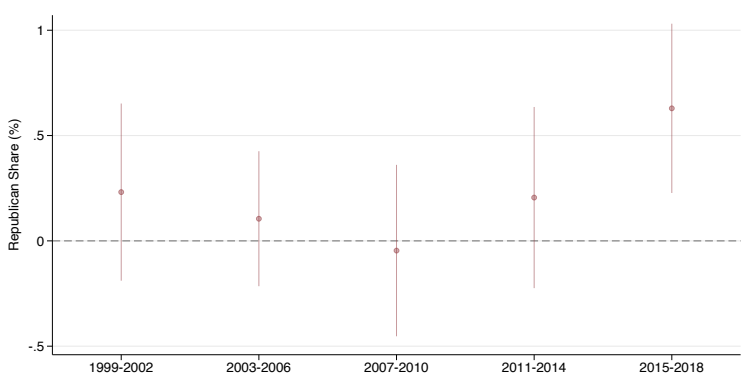




\section{S.5.6. Sample checks}

Figure S.14 shows further robustness tests for the reduced form (RF) estimates for our main electoral results. In this figure, we run a perturbation test, dropping each time one of the 49 states at a time. We plot therefore 49 different sets of regressions. Estimates are in red and $95 \%$ confidence intervals are in green.

Figure S.14: Main Elections Results, Robustness to dropping individual states (RF)

(a) Presidential Elections

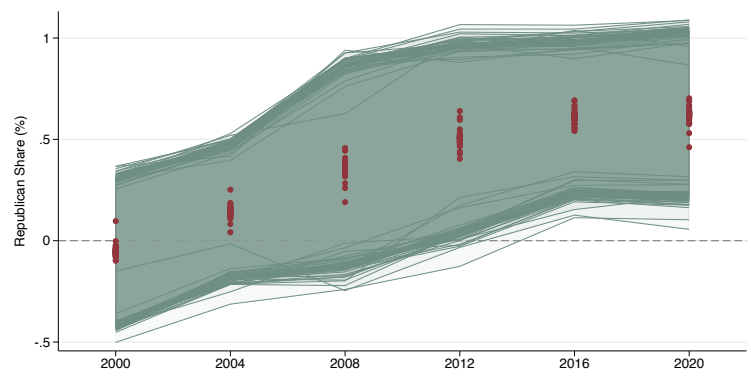

(c) House of Representatives Elections

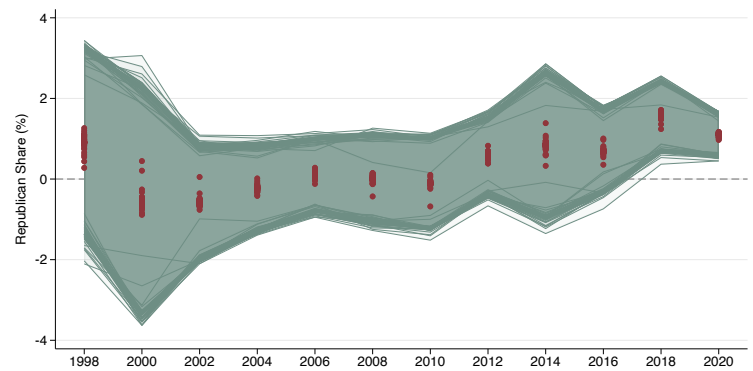

(b) Senate Elections

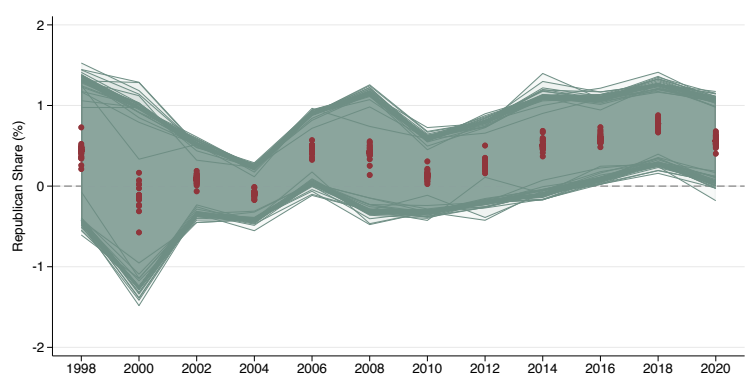

(d) Governor elections

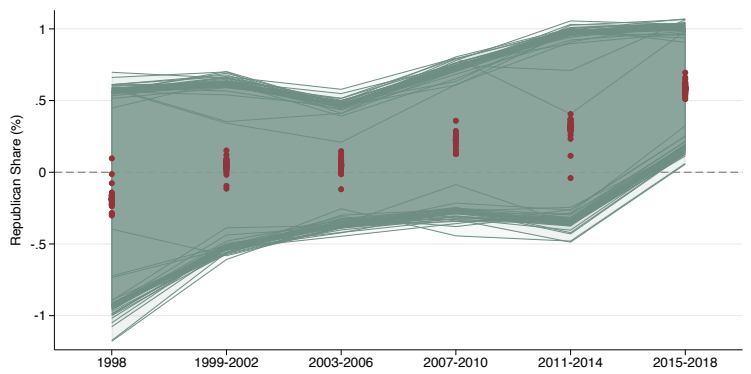

